\title{
Identification of Critical Locations across Multiple Infrastructures for Terrorist Actions
}

\author{
By \\ Sean Albert Patterson \\ B.S., Systems Engineering (2003)
}

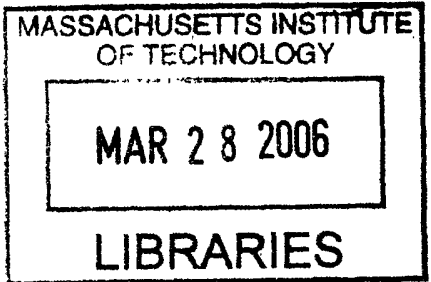

\begin{abstract}
United States Naval Academy
Submitted to the Nuclear Science and Engineering Department in Partial Fulfillment of the Requirements for the Degree of
\end{abstract}

Master of Science in Nuclear Engineering

At the

MASSACHUSETTS INSTITUTE OF TECHNOLOGY

September 2005

(C) 2005 Massachusetts Institute of Technology

All rights reserved

Signature of the Author

Department of Nuclear Science and Engineering

September 2005

Certified by

George E. Apostolakis

Thesis Supervisor

Professor of Nuclear Science and Engineering and Professor of Engineering Systems

Certified by
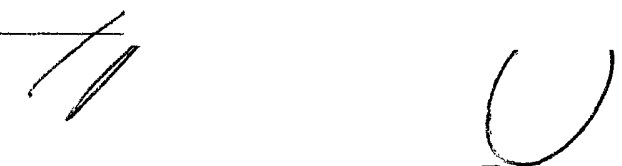

Richard C. Lanza

Thesis Reader

Department of Nuclear Science and Engineering

Accepted by

Jeffery A. Coderre

Professor of Nuclear Science and Engineering

Chairman, Committee for Graduate Students, Nuclear Science and Engineering 
(This page intentionally left blank) 


\title{
Identification of Critical Locations across Multiple Infrastructures for Terrorist Actions
}

\author{
By
}

\author{
Sean A Patterson \\ Submitted to the Nuclear Science and Engineering Department \\ in August 2005 in Partial Fulfillment of the Requirements for the \\ Degree of Master of Science in Nuclear Engineering
}

\begin{abstract}
This paper discusses a possible approach to ranking geographic regions that can influence multiple infrastructures. Once ranked, decision makers can determine whether these regions are critical locations based on their susceptibility to terrorist acts. We identify these locations by calculating a value for a geographic region which represents the combined values to the decision makers of all the infrastructures crossing through that region. These values, as well as the size of the geographic regions, are conditional on a minor destructive threat of a given size, e.g, a bomb that can affect objects within 15 feet of it.

This approach first requires an assessment of the users of the system. During this assessment, each user is assigned a performance index (PI) based on the disutility of the loss of each infrastructure's resource via multi-attribute utility theory (MAUT). A Monte Carlo network analysis is then performed to develop importance measures (IM) for the elements of each infrastructure for their ability to service each user. We combine the IMs with the user PIs to a value that we call valued worth (VW) for each infrastructure's elements independently. Then we use spatial analysis techniques within a Geographic Information System (GIS) to combine the VWs of each infrastructure's elements in a geographic area, conditional on the threat, into a total value we call geographic valued worth (GVW). The GVW is graphically displayed in the GIS system in a color scheme that shows the numerical ranking of these geographic areas. The map and rankings are then submitted to the decision makers to better allocate anti-terrorism resources.

A case study of this methodology is preformed on the Massachusetts Institute of Technology's (MIT) campus. The results of the study show how the methodology can bring attention to areas that may be ignored through individual infrastructure analysis. The intersections of major infrastructures on the campus prove to be of the most importance to the stakeholders of the campus.

Thesis Supervisor: George E. Apostolakis

Title: Professor of Nuclear Science and Engineering and Professor of Engineering Systems
\end{abstract}


(This page intentionally left blank) 


\section{Table of Contents}

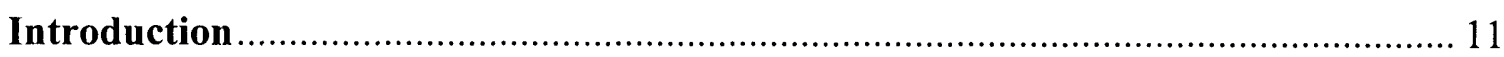

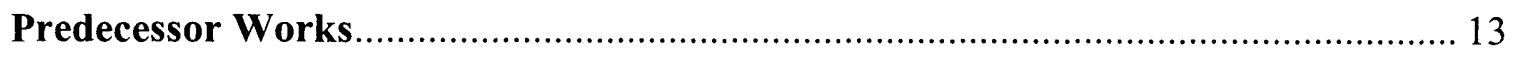

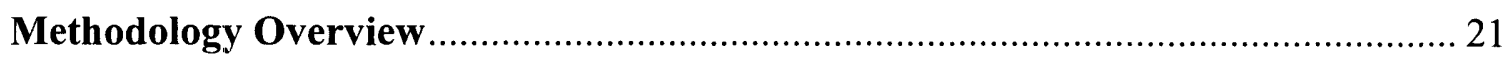

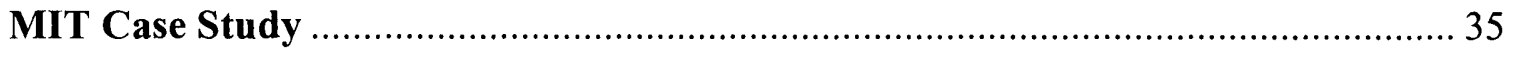

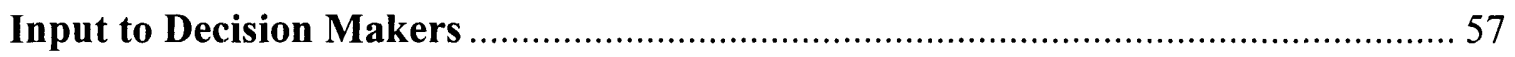

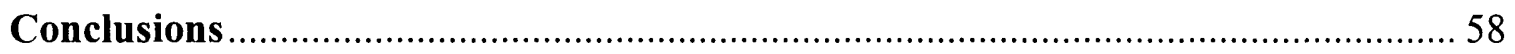

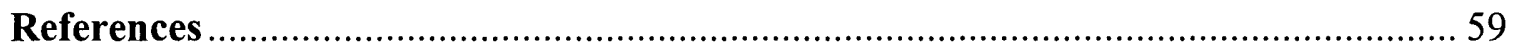

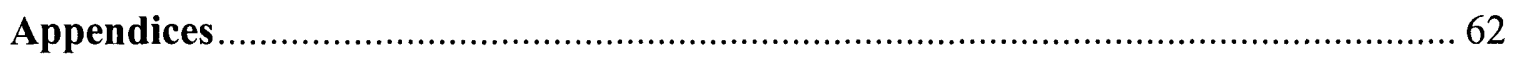

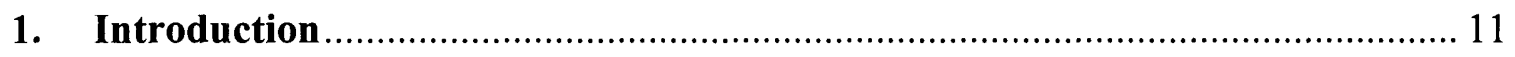

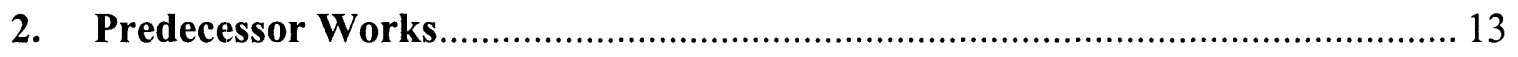

2.1. A Screening Methodology for the Identification and Ranking of Infrastructure

Vulnerabilities due to Terrorism (Apostolakis and Lemon, 2005)............................. 13

2.2. Screening Vulnerabilities in a Water-Supply Network ..................................... 19

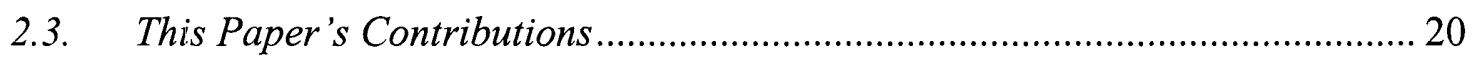

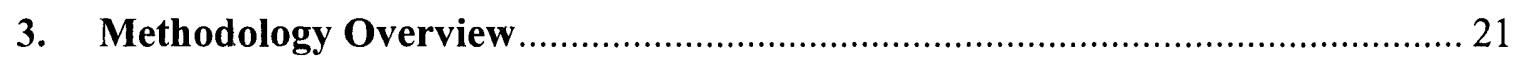

3.1. Performance Index Assessment ............................................................. 22

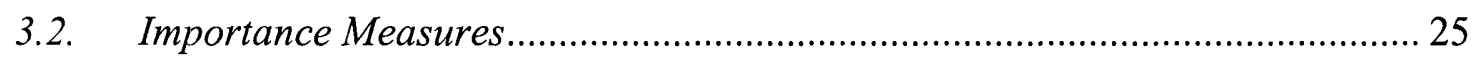

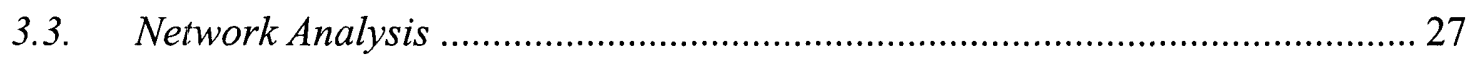

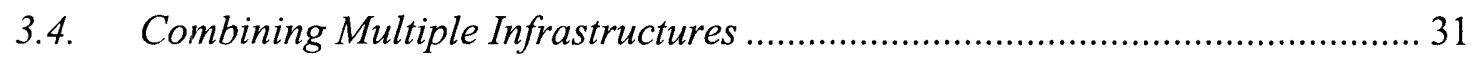

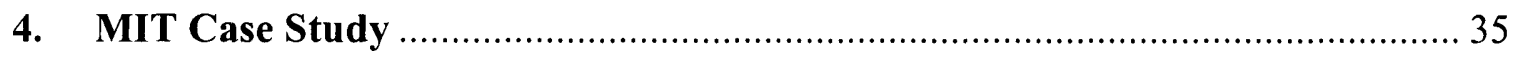

4.1. MIT Infrastructure Background and Analysis Setup ……………………..... 35 


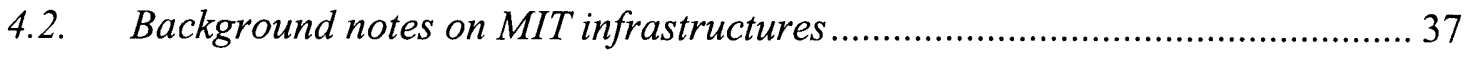

4.3. MIT Value Tree and User PI assessment ................................................... 37

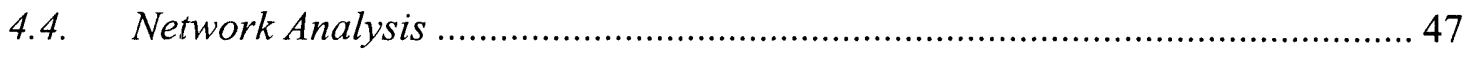

4.5. Individual Infrastructure Results ..................................................... 48

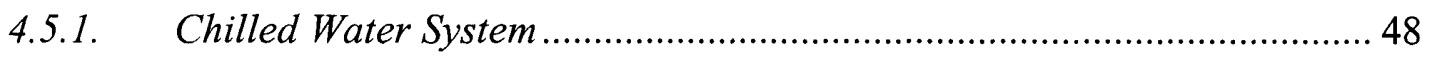

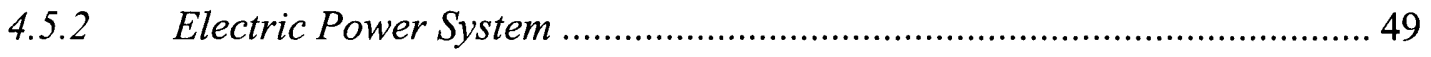

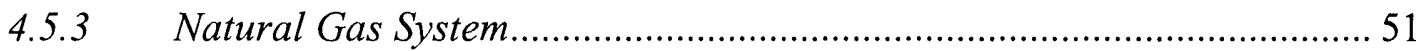

4.5.4 Domestic Water System................................................................ 51

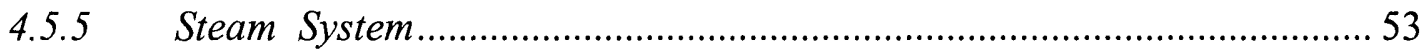

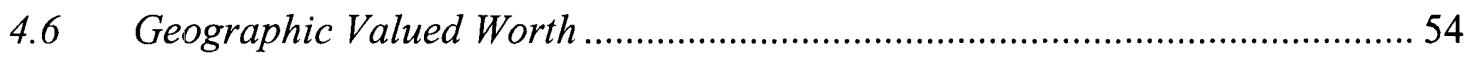

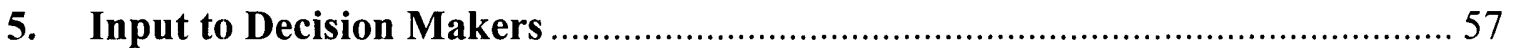

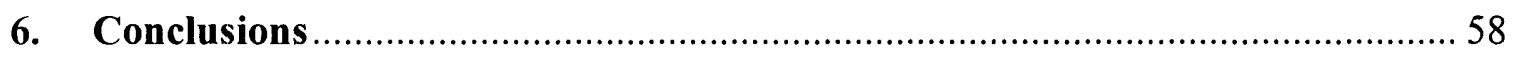

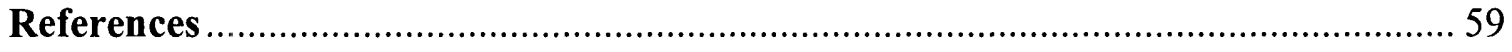

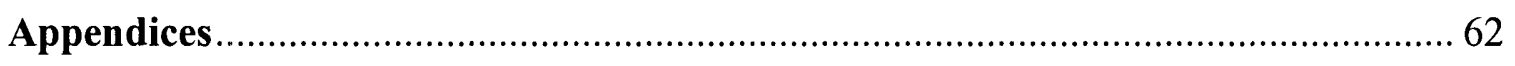




\section{List of Figures}

Figure 1: Value tree and weights for the MIT case study...................................... 16

Figure 2: Impact on People Weighting Function ..................................................... 24

Figure 3: Generic hexagonal grid with a 5-meter radius of influence - zoomed in......... 32

Figure 4: Generic hexagonal grid with a 5-meter radius of influence laid over three

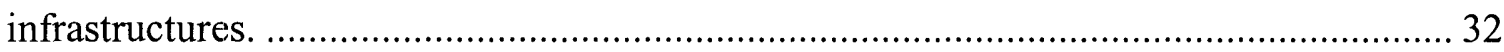

Figure 5: GVW conditional risk map example based on Figure 6 ................................ 33

Figure 6: All users grouped by MG for comparison for all events. The PI on the y-axis is cumulative; each event's PI is added to the others. To get an individual event's PI for a user take look at only the height portion the respective shaded area covers. ................ 46

Figure 7: Chilled Water System VW using RAW ................................................. 49

Figure 8: Electric Power System VW using RAW ................................................. 50

Figure 9: Natural Gas System VW using RAW ..................................................... 51

Figure 10: Domestic Water System VW using RAW …....................................... 52

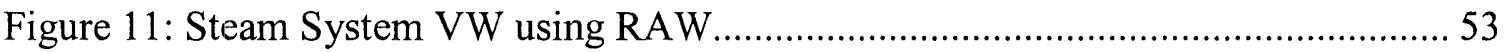

Figure 12: GVW Conditional Risk Map using RAW for the MIT campus.................... 54

Figure 13: Zoom in on left size of campus. GVW in the background.......................... 55

Figure 14: Zoom in around CUP and two choke points in center of campus................. 56 


\section{List of Table}

Table 1: Constructed Scale for Impact on People ..................................................... 16

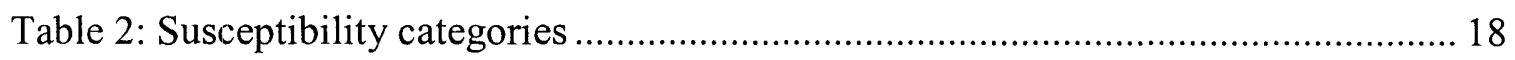

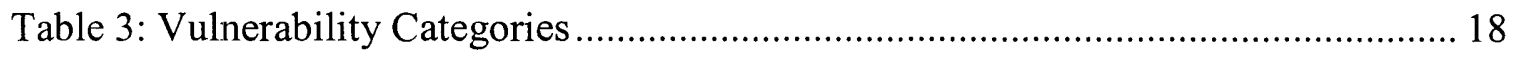

Table 4: Comparison of using and not using a weighting function .............................. 24

Table 5: Constructed Scale for the PM “impact on people." ......................................... 24

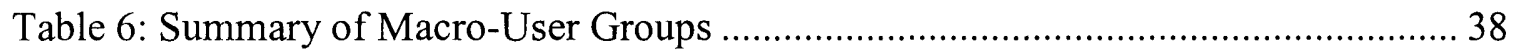

Table 7: Map of Users given by Macro-user Group ................................................ 39

Table 8: Constructed Scale for environmental impact.......................................... 40

Table 9: Constructed Scale for physical property damage ...................................... 40

Table 10: Constructed Scale for interruption of academic activities \& operations ......... 40

Table 11: Constructed Scale for intellectual property damage .................................... 41

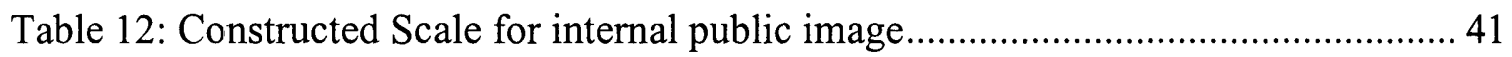

Table 13: Constructed Scale for external public image .............................................. 41

Table 14: Constructed Scale for programs affected................................................. 42

Table 15: Data and respective PM for weighting function use at MIT ......................... 42

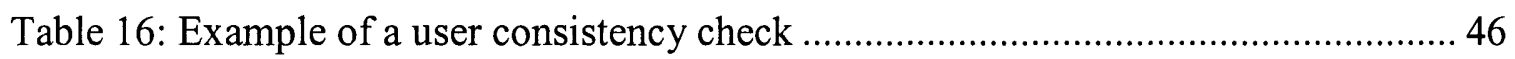




\section{Acronyms}

Acronyms

$\mathrm{A} \& \mathrm{R}$

CHWS

CUP

DOMW

$\mathrm{ft}^{2}$

FV

GIS

GVW

IM

MAUT

MC

mcs

MG

MIT

PM

PRA

RAW

RRW

VW

\section{Definitions}

Academic and Research Macro-User Group

Chilled Water System

Central Utility Plant

Domestic Water System

Square Feet

Fussell-Vesely Function

Geographic Information System

Geographic Valued Worth

Importance Measure

Multi-Attribute Utility Theory

Monte Carlo Analysis

Minimal Cut-Set

Macro-User Group

Massachusetts Institute of Technology

Performance Measure

Probabilistic Risk Assessment

Risk Achievement Worth

Risk Reduction Worth

Valued Worth 


\section{Acknowledgments}

I would like to first thank my advisor, Professor Apostolakis, for his time, effort, and guidance during my research and thesis writing. Thank you to Dan Sheenan, campus GIS support, for his knowledge in GIS programming and operations. I would like to thank Joe Gifun, from the MIT Department of Facilitates, for his help obtaining materials and feedback on my research. I also want to thank Richard Lanza for give his time as a thesis reader.

As always I thank my parents for their love and support during my research. And finally, I send my gratitude and love to my wife for her unending love and support throughout my academics and life. 


\section{Introduction}

After the September $11^{\text {th }}, 2001$ attack, the U.S. Government created a list of infrastructures considered to be critical to the United States. These critical infrastructures are, by default, potential targets (Office of Homeland Security, 2002). These infrastructures are complex and interdependent. This massive intricacy poses a financial allocation dilemma for government and industry. Previous reports such as the one issued by the National Research Council (National Research Council, 2002) offer a large number of recommendations to protect these infrastructures. The cost/risk-reduction of all of these measures is not evident. Implementing all of these recommendations would impose a large financial burden on governments to implement all proposed measures. A screening methodology is therefore needed to determine the allocation of financial resources.

The problem of screening for terrorist vulnerabilities on a critical infrastructure as it impacts society is complex. High-level screening can give an indication as to how resources should be allocated in order to better protect society. One example of this high-level screening was presented by Paté-Cornell and Guikema (2002). This model is characterized as "overarching," i.e., it does not go into the analysis on the physical networks. Garrick et. al. (Garrick et. al., 2004) recommend that a scenario-based methodology known as Probabilistic Risk Assessment (PRA) be used to identify, quantify, and manage terrorist threats. Apostolakis and Lemon (2005) propose the use of PRA to screen terrorism scenarios on infrastructures.

The Apostolakis and Lemon methodology combines multiattribute utility theory (MAUT) and PRA and is demonstrated on the campus of the Massachusetts Institute of Technology (MIT). It determines the disutility of users caused by the loss of each of the infrastructure networks under analysis. Cut set analysis is then performed on the networks and each cut set (consisting of nodes and arcs) is assigned values based on the amount of disutility it creates for its users. Analysis is then performed on the susceptibility of the cut sets to attack and all node/arcs are ranked according to their values. This model uses the physical networks to screen for vulnerabilities. It 
is important to note that nodes (e.g., manholes) that had different infrastructures running through them were given the same node name and therefore geographically common nodes were identified by visual inspection by the authors.

Michaud and Apostolakis (2005) propose that cut set analysis is too stringent in real systems. They stress that sets of node/arc losses that do not fully limit flow can restrict resources to the point that it is virtually a cut set. The case study they use involves the water-supply network of a medium-size city. Due to the capacity limitation, the users do not have unlimited access to water. These limitations may, in effect, cut a user off from the network despite the user' physical positive connectivity to the resource.

Different infrastructures coincide geographically in a complex manner. When the geographic locations of infrastructures are plotted on a map, it can be seen that the infrastructures physically overlap or come spatially very close. Thus, an intentional attack on one infrastructure, specifically with a bomb, will more often than not affect other overlapping or nearby infrastructures.

We propose a screening methodology for identification and prioritization of geographic regions. This is accomplished through the combination of the framework of Apostolakis and Lemon, Monte Carlo network analysis methods, and geographic analysis methods. The analysis is conditional on a destructive threat, e.g., a bomb. Though we develop a numerical rank for the infrastructure elements from this screening, we present it in a graphical form that can show geographic concentrations of elements that cause large increases in risk for the given threat. The ranking is developed through MAUT, which allows us to develop our rankings using the stakeholder and decision maker values.

This paper is arranged by first covering an overview of the methodologies our predecessors at MIT have done followed by a section on our contribution to these methods. Then we present an in-depth methodology overview using examples from our case study. Following 
this, we present the results of our case study. We end with a few conclusions about the proposed methodology.

\section{Predecessor Works}

Two predecessor works have been completed at MIT to define a new approach to infrastructure analysis. Much of these works is the foundation of the proposed methodology of this paper.

\subsection{A Screening Methodology for the Identification and Ranking of Infrastructure}

Vulnerabilities due to Terrorism (Apostolakis and Lemon, 2005)

These authors developed a screening methodology to prioritize critical locations of infrastructures for a minor terrorist attack. They note that the national infrastructures are owned by several stakeholders. Therefore, to include the values of these stakeholders they use MAUT to treat risk as a multiattribute concept and give a consistent basis for the ranking of vulnerabilities. They also assume a minor threat defined to be a single point attack against one or more infrastructures resulting in minimal restoration.

Vulnerability is defined as the "manifestation of the inherent states of the system (e.g. physical, technical, organizational, cultural) that can be exploited by an adversary to harm or damage the system." (Haimes and Horowitz, 2004) A threat is "a potential intent to cause harm or damage to the system by adversely changing its states" (Haimes and Horowitz, 2004). This threat is an initiating event in PRA language (Garrick, et al, 2004). Infrastructures were built for efficiency and convenience, and are therefore are open and accessible particularly during malevolent attack (Haimes and Horowitz, 2004). Therefore, "the concept of vulnerability includes both a measure of how accessible to terrorism a particular target is and the systemdamaging sequence of events that may be initiated after this target is attack. The evaluation of the threat is usually left to the intelligence agencies. The identification of vulnerabilities given a 
threat is a technical problem." (Apostolakis and Lemon, 2005) Their screening methodology focuses on the identification of critical locations. These critical locations are "part of the vulnerabilities. They are defined as geographic points that are susceptible to attacks." Critical locations are not limited to a single infrastructure, but may affect multiple infrastructures at the same location (e.g., a manhole with access to water and gas). We will use these same definitions throughout our paper.

The first step of the methodology is the selection of the assets to be protected. In the case study, they chose the electric, domestic water, and natural gas systems of the MIT campus, and therefore they determined what campus facilities needed an uninterrupted supply of these recourses. The next step is the identification of scenarios initiated by a minor threat that would lead to interruption of the services. To do so, the relevant infrastructures are modeled so that minimal cut set (mcs) analysis is easy to perform. A minimal cut set is a set of events that assure the interruption of supply to a user. All the events in a mcs are required for the interruption. The authors used a network diagraph to model each of the three networks. Supply and user nodes where identified as well as the network vertices and arcs. Vertices which had a common geographic location with other infrastructure vertices are labeled the same name. This identification of geographically common intersections was done by visual inspection.

The mcs must be assigned a value in order to perform a ranking. Apostolakis and Lemon argue that the prioritization should be based on the expected value to the decision maker of the consequences of the vulnerabilities. Such a scheme would require an evaluation of the conditional probability that the terrorists will actually attack a given mcs successfully, something which is inherently difficult to evaluate. The authors, therefore, separate the vulnerability's value from the conditional probability of a successful attack. However, they do provide additional information to the decision maker regarding the degree to which a potential target is accessible, i.e., susceptibility judgments. 
As stated above, Apostolakis and Lemon use MAUT to assess the value of the mcs to the decision maker. A performance index (PI) is calculated for each mcs. The PI is shown in eq. (1) and is the sum of the weights of individual performance measures (PMs) multiplied by the disutility the loss of an infrastructure causes the user in the context of the respective PM.

$$
P I_{j k}=\sum_{i}^{K_{p m}} w_{i} d_{i j k}
$$

where:

$$
\begin{aligned}
& \mathrm{PI}_{\mathrm{jk}} \text { is the performance index for user } j \text { for loss of infrastructure } k \\
& \mathrm{w}_{\mathrm{i}} \text { is the weight of the performance measure } i \\
& \mathrm{~d}_{\mathrm{ijk}} \text { is the disutility of performance measure } i \text { for user } j \text { for loss of infrastructure } k \\
& \mathrm{~K}_{\mathrm{pm}} \text { is the number of performance measures }
\end{aligned}
$$

When $\mathrm{PI}_{\mathrm{A}}>\mathrm{PI}_{\mathrm{B}}$ the decision maker assesses case A to cause more disutility than case $\mathrm{B}$. Examples of these PM from their MIT case study are: impact on people and impact on external public image. The PMs are developed systematically using a value tree, which is representative of the concerns of the stakeholders and is a hierarchal approach to structuring underlying PMs to overall objectives (Gregory and Keeney, 1995; Clemen, 1996). The value tree from the MIT case study, which we will also use in our case study, is shown in Figure 1. This value tree is based on a value tree that had been developed in an independent deliberative process that the MIT Department of Facilities had held with a group of MIT stakeholders (Karydas and Gifun, 2002). The relative weights of the PMs are also produced in the deliberative process. In addition, constructed scales are developed for each PM so that the decision maker can assess how an event affects a user. This event in cases involving infrastructures is the loss of the supply to a user for the infrastructure. The assessment of what level of the constructed scale is affected by an event is left to the decision maker. A constructed scale level is picked for all PMs of each user for each 
event. An example of a constructed scale is in Table 1.

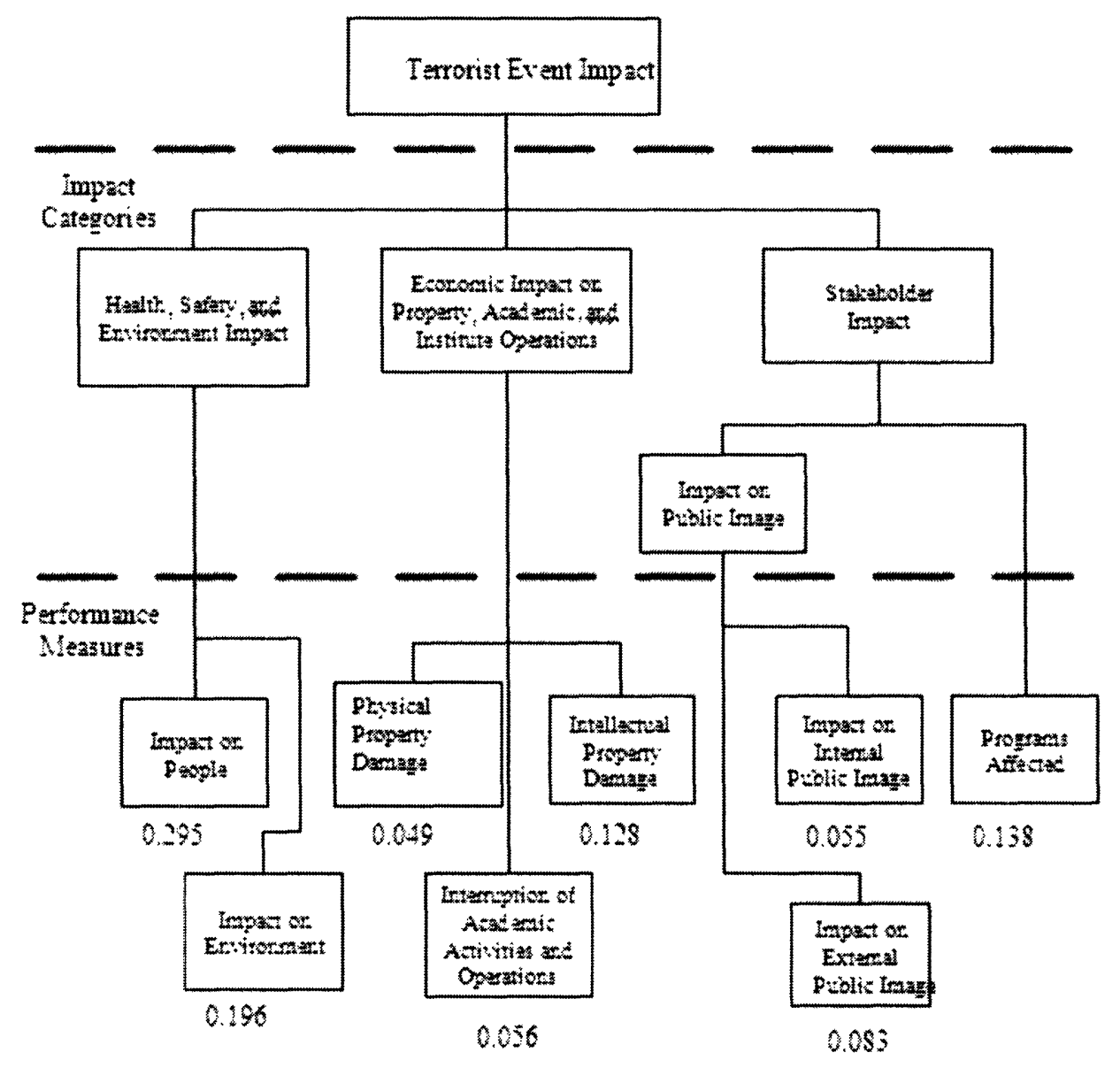

Figure 1: Value tree and weights for the MIT case study.

\begin{tabular}{|c|l|c|}
\hline Level & Description & Disutility \\
\hline 3 & $\begin{array}{l}\text { Fatality or Lethal Exposure, e.g., Roof Collapse, Falling Brick, } \\
\text { Inhalation of Gas }\end{array}$ & 1.00 \\
\hline 2 & Major Exposure with Long Term Effects, e.g., Lead Poisoning & 0.46 \\
\hline 1 & Minor Injury or Exposure, e.g., Broken Arm, Laceration & 0.05 \\
\hline 0 & No personal injury & 0.00 \\
\hline
\end{tabular}

Table 1: Constructed Scale for Impact on People 
Once the decision maker has assessed the PI for all users for all events, the mcs PIs can be calculated. Apostolakis and Lemon use Equation (2) to evaluate these PIs.

$$
P I_{y}=\sum_{j} \sum_{k}\left(m c s_{y}^{j k} P I_{j k}\right)
$$

where:

$$
\begin{aligned}
& \mathrm{PI}_{\mathrm{y}} \text { is the performance index for mcs } y \\
& \mathrm{mcs}_{\mathrm{jky}} \text { is a Boolean operator ( } 1 \text { when the mcs } y \text { impacts the } \\
& \text { user-infrastructure combination } j k \text {, and } 0 \text { otherwise) }
\end{aligned}
$$

Equation (2) sums all the disutilities that a minimal cut set creates to the users of each infrastructure. The result is a PI ranking for all of the mcs. It is evident that, when mos are common among two or more infrastructures, these mcs are of the highest value to the users. In the MIT study, this mainly occurred in the low-order mcs, i.e., mcs that involved one or two elements only.

To address the issue of vulnerability, Apostolakis and Lemon created a scheme to combine the values (PI of the mcs) with susceptibility for each mcs. Their process of determining susceptibility is subjective. Using Table 2, they assign a susceptibly level to each mcs. The authors then combine the susceptibility evaluation with the PI ranking to produce a ranking of the vulnerabilities in a categorical manner presented in Table 3.

\begin{tabular}{|l|l|}
\hline Level & Description (examples) \\
\hline Extreme & Completely open, no controls, no barriers \\
\hline High & Unlocked, non-complex barriers (door or access panel) \\
\hline Moderate & Complex barrier, security patrols, video surveillance \\
\hline Low & Secure area, locked, complex closure \\
\hline Very Low & Guarded, secure area, locked, alarmed, complex closure \\
\hline
\end{tabular}




\begin{tabular}{|l|l|}
\hline Zero & Completely secure, inaccessible \\
\hline
\end{tabular}

Table 2: Susceptibility categories

\begin{tabular}{|l|l|}
\hline Vulnerability & Description \\
\hline Red & $\begin{array}{l}\text { This category represents a severe vulnerability in the } \\
\text { infrastructure. It is reserved for the most critical locations that } \\
\text { are highly susceptible to attack. Red vulnerabilities are those } \\
\text { requiring the most immediate attention. }\end{array}$ \\
\hline Orange & $\begin{array}{l}\text { This category represents the second priority for counter- } \\
\text { terrorism efforts. These locations are generally moderately to } \\
\text { extremely valuable and moderately to extremely susceptible. }\end{array}$ \\
\hline Yellow & $\begin{array}{l}\text { This category represents the third priority for counter terrorism } \\
\text { efforts. These locations are normally less vulnerable because } \\
\text { they are either less susceptible or less valuable than the terrorist } \\
\text { desires. }\end{array}$ \\
\hline Blue & $\begin{array}{l}\text { This category represents the fourth priority for counter terrorism } \\
\text { efforts. }\end{array}$ \\
\hline Green & $\begin{array}{l}\text { This is the final category for action. It gathers all locations not } \\
\text { included in the more severe cases, typically those that are low } \\
\text { (and below) on the susceptibility scale and low (and below) on } \\
\text { the value scale. It is recognized that constrained fiscal resources } \\
\text { is likely to limit efforts in this category, but it should not be } \\
\text { ignored. }\end{array}$ \\
\hline
\end{tabular}

Table 3: Vulnerability Categories

This color coding gives the decision maker a good qualitative judgment based on quantitative facts to determine how best to allocate money to protect the his interests and those of the stakeholders.

A major finding of the Apostolakis and Lemon work was that the mcs with the highest vulnerability was a manhole through which the three infrastructures (electric, natural gas, and water) pass. The mcs for the loss of all three infrastructures to a user was a single node (the 
manhole). This single node caused a large PI in the analysis. Combining this high PI with the finding that the manhole was very accessible and thus at an extreme susceptibility level (Table 2), the authors concluded that this single node belonged to the red vulnerability category (Table 3 ). This is a critical location because it has a high vulnerability due to geographic coincidence of multiple infrastructures and thus depends on the geographic layout of the infrastructures.

\subsection{Screening Vulnerabilities in a Water-Supply Network}

Another work done at MIT (Michaud and Apostolakis, 2005) developed another methodology using the latter work as a basis. This work was specifically developed for a watersupply network but suggests that it may be applicable to other infrastructure types. Therefore, unlike Apostolakis and Lemon, it was not a multi-infrastructure analysis. The goal of the research was to develop a screening methodology for water-supply network vulnerabilities to terrorism. This research specifically took into account capacities and repair, and was calculated through a GIS program. Michaud and Apostolakis added and changed several things from the Apostolakis and Lemon methodology to accomplish this goal, these areas will be pointed our where appropriate.

The infrastructure is first modeled with a Geographic Information System, ESRI ARCGIS in this case. Geographic Information Systems (GIS) are programs that display geospatial information stored in a database in graphical form. Their open architecture allows users to code analysis programs based on spatial requirements. This is in contrast to the digraph models used by Apostolakis and Lemon. The network must have the capacity and repair time of the network elements included as attributes of the element in a GIS database. Flow directions are also setup in the network so looping cannot occur.

Instead of a minimal-cut-set network analysis, this methodology looks for a loss of capacity to a user vice catastrophic loss of a system. Single failures where assumed for each arc 
and node connecting each user to a source. When the program assumed a failure of an arc/node and detected that the user could not receive its full required water supply, it picked a constructed scale level based on the new supply capacity caused by the failure of the respective network element. The constructed scale level picked was a function of the capacity loss to the user as well as the ability/time of workers to repair the element. The PI of the user is then calculated using Equation (1).

\subsection{This Paper's Contributions}

The research presented in this paper uses parts of the above two methods as a starting point, but seeks to expand and change several areas. We take the broad context of the above methodologies by combining network analysis with the PIs of users for the loss of those networks. Therefore, we accept the use of MAUT as the main vehicle to calculate values of the individual users. We will keep the concepts of disutility, value tree, PMs, and stakeholders since they are an effective way to screen these vulnerabilities. We briefly describe our expansions and modifications in the following paragraphs.

Our analysis takes place on a much grander scale than our predecessor works. We analyze 133 users and 5 infrastructures. Because of this, we did not want to assess individually each constructed scale per user, as Apostolakis and Lemon did. We also did not want to dynamically pick the constructed scale within our program like Michaud and Apostolakis. This was due to the required computation time of our network analysis, discussed later. Instead, we will present a method to group users and diversify them using GIS attribute data about the buildings, e.g., the number of people residing in a building, floor space of the building, etc. This is done programmatically before the network analysis and provides diversified users without much input from the decision maker.

We agree with the divergence from the minimal-cut-set analysis that Michaud and Apostolakis performed. We too will diverge but not base our analysis on capacity and single 
component failures. We will present a method to develop importance measures using Monte Carlo network analysis that will give us answers about what the failure of elements means to the system.

Like Apostolakis and Lemon, we develop a multi-infrastructure analysis. However, we do not identify common nodes by inspection followed by a minimal-cut-set analysis. We instead

perform a network analysis on all infrastructures independently and then, through GIS algorithms, we find geographically coincident and even spatially close nodes/arc, e.g., parallel pipes within a certain distance from each other. Doing this "intersection analysis" after the network analysis allows us to easily change the "intersection distance," i.e., how close different elements must be to be considered spatially coincident.

Like Michaud and Apostolakis, we use GIS as a tool and programming platform. We too present our findings in a graphical display. However we will develop a grid which will determine the increase in risk to society for geographic regions. These regions (grid spaces) are conditional on a minor threat (ex. a single bomb attack) and have a value based on their ability to increase in risk to society for minor threat of a given radius of influence. This radius is the range of a destructive threat, e.g. a bomb, which destroys elements of infrastructures within the radius. For example, a bomb that can affect a $5 \mathrm{ft}$ radius, any infrastructures within 10 feet of each other must be analyzed by a concurrent initiating event. The map we later present is therefore conditional on the type and size of the threat.

The rest of this paper will describe how we calculate the values of these geographic regions which will be displayed in a conditional map.

\section{Methodology Overview}

Here we present an overview of the proposed methodology for screening critical locations using GIS. 


\subsection{Performance Index Assessment}

First we identify the infrastructures of interest. These infrastructures must be in a GIS database or convertible file format. Each infrastructure should have at least one supply within the scope of the analysis.

We use the same equation, Equation (1), as Apostolakis and Lemon. Before we go on to assess constructed scales, we pause to reflect on our task of assessing hundreds of users for many events. In order to create a manageable PI assessment for our 133 users and all five events, we decided that we should not individually analyze each user for its PI. Rather we created a user hierarchy by grouping users into Macro-user Groups (MGs) based on the main function of the building. For example, dorms would be in the residential MG and a building of classrooms would be in the academic and research MG. With this hierarchy established, we now only assess the PMs of users by group, i.e., all the users within an MG have the same constructed scale level picked for a given event. By grouping the users into their respective $\mathrm{MG}$, we reduce the number of decisions that must be made by the decision maker since the users within the MG are dependent on the MG itself not the decision maker's individual assessment.

Due to the MG scheme presented above, so far all, the users in the same MG have the same PI for a given event, i.e., loss of an infrastructure. Obviously, it is not the case that all residential MGs have the same value to the decision maker for the same event. With the use of GIS and the addition of the MG scheme we can add another layer of diversification to all users. To do this, we apply a natural scale to the constructed scale. A natural scale, such as the amount of classroom square footage in a building, can be multiplied by the constructed scale to yield a weighted disutility for a certain PM. We call this natural scale the weighting function since it weights the impact of the constructed scale by some data. Therefore " $d$ " in Equation (1) is now called the weighted disutility and is equal to the unweighted disutility from the constructed scale times the value from the weighting function. The key here is to use data that are available within GIS or some accessible database. By doing this the scaling process the weighting function 
performs on the PMs is not a decision the decision maker makes for each user. Rather it is a mathematical calculation made on the data of the user. The mathematical function itself is set during the frame working process that the stakeholders perform. Once the function provides positive consistency checks, as is the case for all of the weighting in the value tree, it does not change during the actual PI assessment process, thereby eliminating individual assessment by the decision maker.

As said, this weighting function is established during the frame working process by the stakeholders for PMs where they believe it is applicable and where it leads to consistent results. A PM can have a weighting function based on one type of data or a combined data. The weighting function must however scale this data so that output is greater than zero and saturates at one. The functions can be anything from linear to non-linear as long as the PIs are consistent.

Let us look at this concept in an example. In Table 4, we present two dorm buildings both within the residential MG. One building houses 500 people and the other 50 people. We calculate the PI for the scenario where the only PM impacted is the "impact on people" whose constructed scale is shown in Table 5 . We assume that an event leads to an impact assessed as level 3. Without a weighting function the PI is calculated by using Equation (1) and the value tree from Figure 1. Therefore each building has a PI of 0.295. Thus, before the weighting function is applied, the two dorms, by virtue of being in the same MG, have the same PI.

Now, we assume the same arbitrary event thus choosing the level 3 impact on the "impact on people" PM and keeping the other PMs at level 0 , but this time we apply a weighting function (Figure 2) based on the number of people affected. In this case, the two dorms have different PIs for the same event. What this really means is that by using a population weighting function, the 500 person dorm evokes more disutility because more people are affected. 


\begin{tabular}{|l|l|l|l|l|}
\hline & $\begin{array}{l}\text { Population } \\
\text { Data }\end{array}$ & Old Total PI & $\begin{array}{l}\text { Weighting } \\
\text { Function }\end{array}$ & New Total PI \\
\hline Dorm A & 500 people & 0.295 & .99 & .292 \\
\hline Dorm B & 50 people & 0.295 & .63 & .186 \\
\hline
\end{tabular}

Table 4: Comparison of using and not using a weighting function

\begin{tabular}{|c|l|c|}
\hline Level & Description & Unweighted \\
& & Disutility \\
\hline 3 & Fatality or Lethal Exposure & 1.00 \\
\hline 2 & Major Exposure with Long Term Effects; Loss of jobs & 0.46 \\
\hline 1 & Minor Injury or Exposure; Significant Employment interruption & 0.05 \\
\hline 0 & No personal injury or job loss & 0.00 \\
\hline
\end{tabular}

Table 5: Constructed Scale for the PM "impact on people."

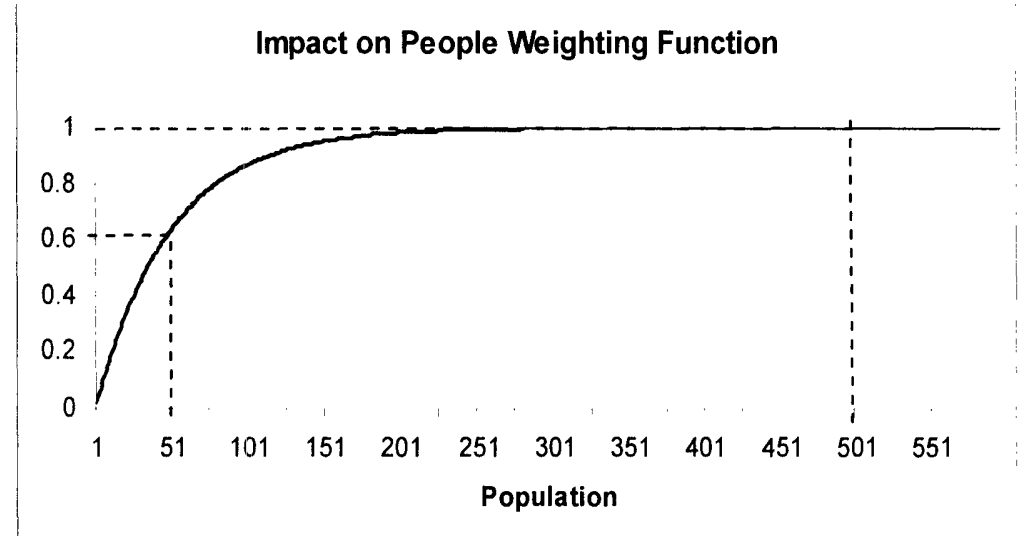

Figure 2: Impact on People Weighting Function

These functions are not required to be used for all PMs or MGs. It is even possible to setup constructed scales to handle this data based weighting during the initial framework process. For example, we can see that currently the constructed scale in Table 5 has levels based on the intensity of the impact on the PM. Instead we could create three PMs: Minor impact on people, 
Major impact on people, and Fatalities. These three PMs would then have levels where the descriptors would be the number of people impacted in the context of the PM, i.e., the lower the level the fewer people impacted. However, trying to keep this data scaling and adjusting the constructed scale to accommodate this data will most likely lead to an increase in the number of PMs, as in the example just given. In our case study, we wanted to keep the constructed scales and PMs set up by Apostolakis and Lemon thus we use a weighting function on their established constructed scales.

No matter what way PIs are assessed, with or without MGs and weighting functions, consistency must be established. It may be found that using or not using our suggestions can either more easily or less easily establish consistent PIs. Each decision analysis process is unique, thus it is hard to say that the MG scheme and weighting functions will help other PI assessment processes. However, we found it useful in our case study and we will use both the MG and weighting function schemes.

\subsection{Importance Measures}

It has been stated that minimal-cut-set analysis becomes obsolete as the network becomes larger and highly distributed. (Billinton, 1992; Marseguerra and Zio, 2002) Cut-set analysis is also computationally intense. To evaluate the network elements we develop importance measures (IMs). These measures are quantifications of how the availability or unavailability of the elements affects the network. This section describes several IMs that will be calculated using Monte Carlo simulations.

There are several importance measures that have been developed in the literature. We will calculate four of them: Fussell-Vesely (FV) Eq. (3), Birnbaum Eq. (4), Risk Achievement Worth (RAW) Eq. (5), and Risk Reduction Worth (RRW) Eq. (6). FV and RRW are related mathematically. Birnbaum completely depends on network structure. (Cheok, Parry, and Sherry, 1997). Descriptions of what the each IM means is given below their respective equation. 


$$
F V_{y k j}=\frac{U_{k j}-U_{y k j}^{-}}{U_{k j}}=1-\frac{1}{R R W_{y k j}}
$$

Fussell-Vesely (FV) describes the maximum fractional decrease in risk to the user $j$ for infrastructure $k$ when element $y$ is made always available.

$$
\mathrm{RAW}_{\mathrm{ykj}}=\frac{\mathrm{U}_{\mathrm{ykj}}^{+}}{\mathrm{U}_{\mathrm{kj}}}
$$

Risk Achievement Worth (RAW) describes the ratio of risk to user $j$ for infrastructure $k$ to the risk to the user when element $k$ is always unavailable.

$$
B_{y k j}=U_{y k j}^{+}-U_{k y j}^{-}
$$

Birnbaum describes the maximum change in risk to user $j$ for infrastructure $k$ when element $y$ switches from available to unavailable.

$$
\mathrm{RRW}_{\mathrm{yku}}=\frac{\mathrm{U}_{\mathrm{kj}}}{\mathrm{U}_{\mathrm{ykj}}^{-}}
$$

Risk Reduction Worth (RRW) describes the ratio of risk to user $j$ for infrastructure $k$ to the risk to the user when element $k$ is always available.

(Zio, Podofillini, and Zille, 2006)

where:

$\mathrm{U}_{\mathrm{kj}}$ percent of simulations in which there is no path connecting the user $j$ to an infrastructure $k$ source

$\mathrm{U}^{+}{ }_{\mathrm{ykj}}$ percent of simulations in which element $y$ of infrastructure $k$ is failed and there is no path connecting the user $j$ to an infrastructure $k$ source

$\mathrm{U}_{\mathrm{ykj}}^{-}$percent of simulations in which element $y$ of infrastructure $k$ is not failed and there is no path connecting the user $j$ to an infrastructure $k$ source

The IMs are calculated using $U_{k j}, U^{+}{ }_{y k j}, U^{-}$ykj. Since we will be performing multiple Monte Carlo simulations, described below, to calculate these IMs these values are calculated by keeping counters for each element as well as the system and dividing them appropriately. For the system there is a total counter $U_{\text {total }}$, which is also the number of simulations run for any given user-infrastructure combination. There is a counter $U_{\text {system-fail }}$ which tracks the number of simulations where the user is not connected to a supply. For each element of the infrastructure 
there are four counters, two when it is failed and two when it is working. The counter $U_{k \text {-fail }}$ tracks the number of times the element is failed and the counter $U_{k \text {-fail-system-fail }}$ tracks whether the element is failed while the system is failed. There is counter $U_{k \text {-working }}$ which tracks the number of

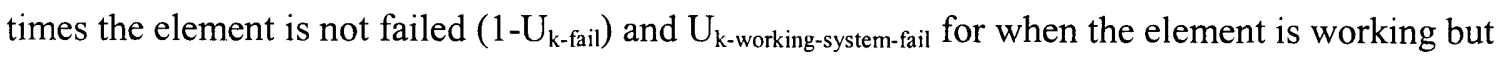
the system is failed. $U_{k j}, U^{+}{ }_{y k j}, U_{y k j}^{-}$are therefore given by the following Equations (7) through (9):

$U_{k j}=\frac{U_{\text {system-fail }}}{U_{\text {total }}}$ (7) $\quad U_{y j k}^{+}=\frac{U_{k-\text { fail-system-fail }}}{U_{k-\text { fail }}}$ (8) $\quad U_{y j k}^{-}=\frac{U_{k \text {-working-system-fail }}}{U_{k \text {-working }}}$

(Zio, Podofillini, and Zille, 2006)

In our case study (presented later), we calculated all four IMs listed above, however the first thing we noticed about our final rankings was that two the results using two IMs yielded the same ranking. These two (RRW and FV) gave us a sanity check since, as shown in eq. (3), they are mathematically related. The results based on RAW also gave a ranking which was similar to the results based on RRW and FV. Thus, in order to give the decision makers an easily assessable number set we will present our equations and findings using the RAW. We also note that RAW is "commonly used as an intuitive measure of margin provided by the component." (Cheok, Parry, and Sherry, 1997) However, in the equations below, RAW can be replaced by any of the other three importance measures, as long as that IM is consistently used for all equations, in order to get a different insight into the system.

\subsection{Network Analysis}

In order to develop the above counters and thereby get the IMs (RAW) of the elements, simulations must be preformed for each user $j$ per each infrastructure $k$. These simulations are random network states created through Monte Carlo (MC) trials. We present a time-independent simulation. This means that there needs to be a probability associated with the random failures that are induced in each independent simulation. This value could be thought of as a probability 
of a successful attack, i.e., the probability that, conditional on the threat, the threat would induce a failure; e.g., a suitcase bomb placed atop a manhole would fail the component(s) and/or pipe(s) of an infrastructure(s) inside of the manhole. This probability can be associated to a target's susceptibility to the conditional threat. If we run a Monte Carlo simulation where all components have the same probably of failure, i.e., all elements have an equal likelihood of failing from the same threat, then the random failures which occur in a reliable simulation will yield the same ranking (presented later) even if the probably is changed (keeping the same value for all components) and only yield different importance measure values. This means that as a first cut we can get a ranking of components without expert analysis as to the susceptibility of the elements under analysis. Ignoring susceptibility at this point means that the rankings we develop later do not suggest an element is vulnerable or not vulnerable, rather the elements pose a lesser or greater risk to the network due to their unavailability.

In future work, with expert analysis we could assign the proper probability of a successful attack to each network element independently. This does not mean the probability of an attack (ability of a group to desire to, obtain materials, and carry out an attack) needs to be assessed. We define the probability of a successful attack only by the ability of the threat (e.g., bomb) to destroy a target. It is the susceptibility of a target to a conditional threat, not the probability of the threat to be created. For example expert analysis would most likely render pipes under a street less probable to failure than pipes passing through an access point (manhole). By doing this the final rankings will be representative of the vulnerabilities since the simulations will now be based on the susceptibilities of the elements. If this is done care should be taken to realize that if the susceptibilities change for any reason, e.g. countermeasure are installed, all simulations must be run again.

Each simulation is one random network state. With a given user $j$ and a single infrastructure $k$, we pick a random number, $\mathrm{R}_{\mathrm{ky}}$, for each network element $y$ of infrastructure $k$. For each element, the random number $\mathrm{R}_{\mathrm{ky}}$ is compared to the probability of a successful attack, 
$\mathrm{PF}$, described above. If $\mathrm{R}_{\mathrm{ky}}<\mathrm{PF}$, then the element is considered failed for the current simulation. Once all network elements have been appropriately failed the simulation state is considered set. The GIS program then uses an internal algorithm to check whether there is a path that connects user $j$ to a supply node of infrastructure $k$. An existent path implies a working system and a nonexistent path implies a failed system.

Once this path is checked the simulation is complete, we then proceed to update all of the counters $\left(U_{\text {total }}, U_{\text {system-fail }}, U_{k \text {-fail, }} U_{k \text {-fail-system-fail, }} U_{k \text {-working, }} U_{k \text {-working-system-fail }}\right)$ once, where appropriate. The state of the system is then reset so all elements are available. A new MC trail is preformed with new random numbers and again updating the counters appropriately. This process continues until all MC trials, $\mathrm{N}$, have been performed for current user $j$ and infrastructure $k$.

We then use the counters from the $\mathrm{N}$ trials to calculate the RAW for each element of the infrastructure $k$. Then we multiply the RAW for each element by the PI of user $j$ given infrastructure $k$. This multiplication scales the RAW by the amount of disutility (PI) the loss of the infrastructure $k$ creates for user $j$, i.e., the amount of disutility user $j$ experiences because no path exists from any supply of infrastructure $k$ to the user $j$. We therefore term the resultant calculation "worth" and describe it in Equation (10). Equation (10) also points out the addition of our weighted disutility versus equation (1) without the weighting function scheme.

$$
W_{y k j}=R A W_{y k j} * P I_{j k}=R A W_{y k j} * \sum_{i}^{K_{p m}} w_{i} d_{i j k}
$$

where:

$\mathrm{w}_{\mathrm{i}}$ is the weight of PM $i$ from the value tree $\mathrm{d}_{\mathrm{ijk}}$ is weighted disutility of PM $i$ for user $j$ for loss of infrastructure $k$ $\mathrm{W}_{\mathrm{jky}}$ is the worth of element $y$ of infrastructure $k$ for user $j$ $\mathrm{PI}_{\mathrm{jk}}$ is the performance index for user $j$ for loss of infrastructure $k$ $\mathrm{RAW}_{\mathrm{ky}}$ is the importance measure RAW of element $y$ of infrastructure $k$ for user $j$ 
After all of the worths have been calculated for each element of infrastructure $k$ we then reset the MC trial counter and perform the above simulations and calculations for another user $j+1$ for the same infrastructure $k$. This is done for all users that are serviced by infrastructure $k$. Once complete, we do a summation of all of the worths for each element for all users infrastructure $k$ services. This summation assumes independence between the users just like we assume independence between PMs in Equation (1). This requires that if, for example, user $a$ loses service from an infrastructure, the loss to user $a$ alone cannot affect user $b$ 's service. User $b$ service may only be affected by the network itself. Thus for user $b$ to lose service, the infrastructure must have the appropriate components unavailable so that there is no path from a supply to user $b$; user $b$ cannot simply lose an infrastructure just because user $a$ lost service, i.e. only the network itself can affect a user; users cannot affect other users. We call the result of this summation "valued worth" and it is given by Equation (11).

$$
V W_{y k}=\sum_{j} W_{y k j}=\sum_{j}\left[R A W_{y k j} * \sum_{i}^{K_{p m}} w_{i} d_{i j k}\right]
$$

where:

$$
\begin{aligned}
& \mathrm{VW}_{\mathrm{yk}} \text { is the valued worth of element } y \text { of infrastructure } k \\
& \mathrm{~W}_{\mathrm{ykj}} \text { is the worth of element } y \text { of infrastructure } k \text { for user } j
\end{aligned}
$$

After the valued worth is calculated for each element of infrastructure $k$, we then reset the MC trials and advance to infrastructure $k+1$. All of the above calculations and MC simulations are preformed for each user serviced by infrastructure $k+1$, i.e., run N MC trails for each user tracking the counters and then calculating the worth of each element; once all users have been simulated $\mathrm{N}$ times then the valued worth of all elements of infrastructure $k+1$ is calculated. 
The valued worths of a given infrastructure can be ranked and displayed in conditional risk maps. These maps give the decision makers an independent view of each infrastructure. The valued worths represent RAW scaled by the potential disutility they evoke to all users of their respective infrastructure. The higher the valued worth, the higher the probability that the unavailability of the network element will fail the network to the users it services with some disutility (PI) potentially caused to those users. It is important to note here that these values calculated through RAW do not give a yes/no answer. As said, the values represent the potential of an element's unavailability to fail the system and cause a certain amount of disutility; the failure of a high value item may or may not lead to a user(s) losing service to an infrastructure.

\subsection{Combining Multiple Infrastructures}

Once the valued worth for all elements of all infrastructures have been calculated we proceed to the full power of GIS, using spatial analysis, to develop our final results. First, we must develop a generic grid to be laid across the map of all the infrastructures. The side of each grid space is the size of the threat's radius of influence. We use a hexagonal close packed grid across the entire region of analysis. A generic grid is displayed in Figure 3. Figure 4 shows a grid laid over three infrastructures. 


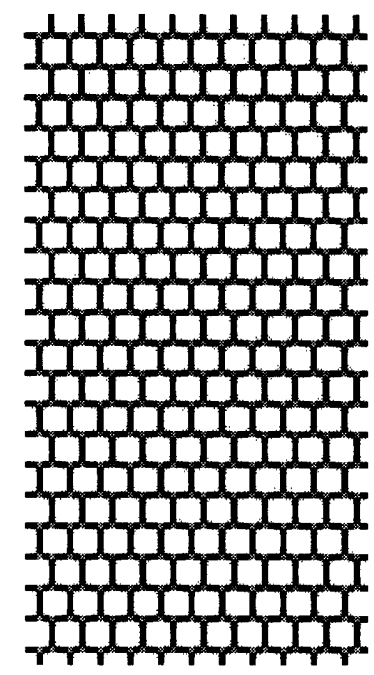

Figure 3: Generic

hexagonal grid with a

5 -meter radius of

influence - zoomed in.

We use an internal GIS function to first take the maximum valued worth of all elements of the same infrastructure that pass through or are located within each hexagon. We then sum the maximum valued worth elements from each infrastructure for each hexagon. Since the valued worths are now only relevant to their geographic location we call the result of this process the "geographic valued worth" (GVW). Equation (12) describes this process.

$G V W_{x z}=\sum_{k} \max \left(V W_{y_{x z} k}\right)=\sum_{k} \max \left[\sum_{j}\left[R A W_{y_{x z} k j} * \sum_{i}^{K_{p m}} w_{i} d_{i j k}\right]\right]$

where:

$\mathrm{GVW}_{\mathrm{xz}}$ is the geographic valued worth of the grid space at coordinates $(\mathrm{x}, \mathrm{z})$

$\operatorname{Max}\left(V W_{y(x z) k}\right)$ is the maximum valued worth element $y$ out of all the elements of infrastructure $k$ that pass through grid element $(\mathrm{x}, \mathrm{z})$ 
Unlike the valued worth, GVW is a multi-infrastructure value. GVW is always conditional on the threat and thus the radius of influence. The GVW can be ranked in tabular format but the most intuitive presentation is through a color ramp of the GVW values and displaying thern in a GVW conditional risk map. The color ramps used in our figures are grayscale where the lightest gray represents the lowest numerical group and solid black is the highest numerical group. The intermediate groups are represented in increasing numerical order by increasing darkness between the light gray and black groups. . An example of this type of display is in Figure 5. Figure 5 is the GVW calculation of Figure 4.

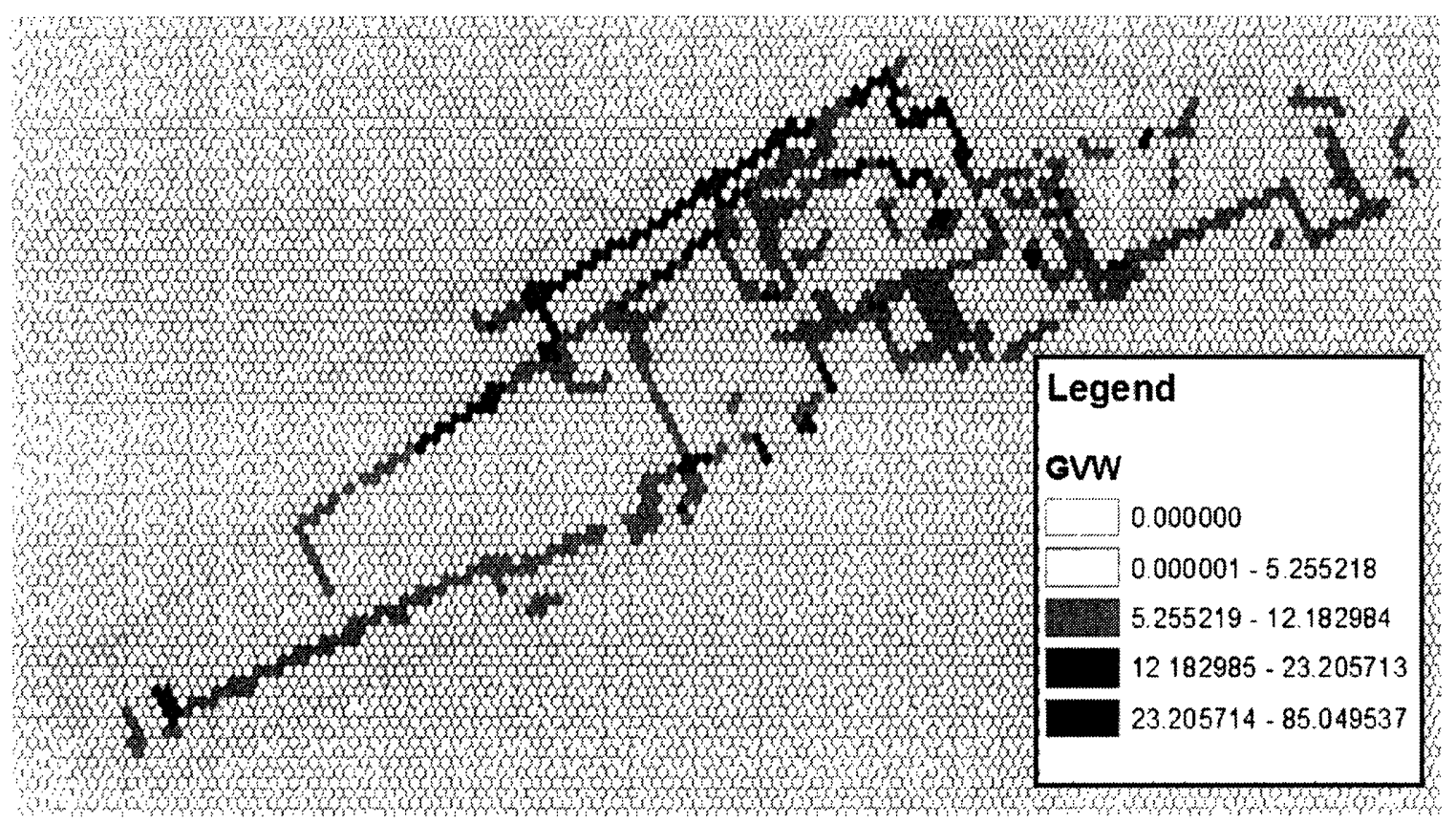

Figure 5: GVW conditional risk map example based on Figure 6

The color ramp is performed using Jenks Breaks of the GVW data and is a GIS internal algorithm that finds groups of numbers. This is not a linear ramp. It finds natural breaks in the data by finding groups of close numbers while maximizing the distance between these groups. This distance is dependent on the number of groups the user asks the program to create. With a given number of groups, the algorithm places the boundaries of the groups where there are relatively large jumps in the data, thereby maximizing the distance between the groups. For our 
purposes, it easily breaks out high value groups of GVW hexagons as well as other smaller groups.

Due to the nature of Jenks Breaks the groups depend on the values in the data. Therefore, if multiple Jenks Breaks are presented on a map for multiple data sets, the Jenks Break's groups created are only valid for their respective data set. For example, in Figure 6 there are three different infrastructures presented simultaneously. In this figure, each of the three infrastructures has a Jenks Breaks preformed on its own dataset, therefore though not obvious, the figure has three color ramps displayed simultaneously, one for each infrastructure. The difficulty in observing these three different infrastructures at the same time gives a good basis for why we perform the GVW calculations and present them in their own map. This new map presents a spatial combination of all three infrastructures, e.g. Figure 5 for the case of Figure 4's infrastructures. We the reason the valued worths of the three infrastructures do not have the same number range is due to the network layout, number of users, and the disutility levels its unavailability creates to the users it supplies. Therefore the high and low areas of each infrastructure independently are important to the stakeholders of that particular infrastructure. Yet, when we apply a Jenks Break to the GVW in Figure 5 we see that, for example, the high group (black) locations are different than the high group locations of the individual infrastructures in Figure 4. Again, this is something not readily observable by looking at Figure 4 with its three different infrastructures. The GVW covers a different number set therefore the Jenks Breaks groupings are different.

This whole methodology can be computationally time consuming until after the Monte Carlo simulations have been run. However, at this point, we can easily change the size of the radius of influence to change the grid size and get new GVW within seconds. The new GVW is conditional on the new radius of influence.

We will now apply the time-independent methodology to the MIT campus. 


\section{MIT Case Study}

We used the MIT campus as a case study due to the accessibility of infrastructure layouts. We had an open dialog with the MIT Department of Facilities (DOF), which provided us with information regarding specifics of the infrastructures. The case study was originally preformed on the real MIT infrastructure layouts. Interpretation of the results made intuitive sense and yielded consistent results with our value tree. These real infrastructure results are not presented here. For security purposes, we have changed the geographic layouts of the infrastructures. However, we kept several things the same to yield results that we could interpret. These are: the user PI; the number of arcs and nodes; the number of users serviced by an infrastructure; the number of supplies per infrastructures particularly the main on-campus generated resources.

We will use the same value tree as Apostolakis and Lemon (2005). This value tree considers an MIT building a user, thus also we consider any building under MIT jurisdiction a user. There were 133 building covered by this case study. Not all users were supplied by all infrastructures and some users were supplied redundantly. The constructed scales were developed by Apostolakis and Lemon. We have kept their zoned levels but modified the descriptions to fit our MG scheme.

The case study is presented in the following fashion. First, we present a background on the MIT infrastructures we have chosen to analyze. Then, we present the MG grouping, value tree, constructed scales, and weighting functions as well as their results (user PIs). Following this, we present the results of each infrastructure independently, i.e., their valued worth. We then present the GVW of the MIT campus.

\subsection{MIT Infrastructure Background and Analysis Setup}

We selected the following infrastructures for the case study: Chilled Water Supply, Domestic Water Supply, Steam Supply, Natural Gas, and Electric Power. We felt that telephone 
and data systems, which can also be wireless, presented a different set of problems that could not be addressed through the type of analysis presented here because their users and sources are not well defined. We also ignored the "return resources," i.e., chilled water return, sewer and storm drain, and steam condensate, again due to a more complicated user/supply scheme.

The physical networks for the analyzed infrastructures were taken directly from the DOF $\mathrm{CAD}$ drawings and are presented here with modifications for security purposes. Again, for this study, all of the campus buildings were considered users. The physical place where we placed the user nodes for each network on our GIS maps is where the MIT DOF campus wide plans reference to a building floor plan. This occurs, in the majority of cases, after the first isolation valve or access node within the physical building.

Several buildings, for various infrastructures, are serviced by multiple sources or multiple pipes/lines from the same source. Given the same infrastructure, all of the service lines ending within a building are considered to service the same user, and a loss of a resource to that building would require the loss of that resource through all lines of the respective infrastructure servicing the building. Also, in some places, resources do not physically connect to a building but still service it; we assume the closest building to the point user to be serviced by the resource. For example a fire hydrant outside of buildings would be considered a fire resource for the nearest building.

For the most part, flow direction was not considered in this analysis but the coding has been done for this and will be implemented in later research/results. The only part of this research where there is directed flow is where it is labeled thusly on the CAD drawings, which only occurs in the steam system. Also, dead-end/end-capped resources are modeled to the point where they are isolated from the rest of the system by a valve. Non-user nodes are placed where there is any access to or equipment for the system. Examples are manholes, hand holes, meters, isolation valves, switch boards, etc. Nodes are also located at any intersections of piping. 


\subsection{Background notes on MIT infrastructures}

Electric:

- Central Utilities Plant (CUP) can supply up to $80 \%$ of full power

- Extra power is purchased and supplied offsite

- There are two main buses which service four major loops and each bus services one half of each loop under normal conditions

Domestic Water:

-All domestic water is supplied from several pipes from off campus suppliers

-The domestic water supplies water to the fire suppression system and there are several dedicated fire suppression loops

Steam:

-MIT produces all of its steam from the Central Utilities Plant

Natural Gas:

-All natural gas is supplied from off site on several lines

\section{Chilled Water:}

-MIT produces all of its own chilled water

-The main supply is from the Central Utilities Plant

-There is a smaller plant that is located and services several building on east campus

\subsection{MIT Value Tree and User PI assessment}

There were 133 building analyzed and each building is considered a user. Not all buildings receive all infrastructure resources; major examples of this are the chilled water and steam systems. Due to the large number of users, we did not want to analyze each user individually. Instead, we setup a hierarchy of users. For MIT, we divided the buildings into four macro-user groups (MG): Residential (dorms, etc), Academic and Research (classrooms and 
laboratories), Support Facilities (utility plants, etc), and Athletics (sports, gym, etc). We later assigned different disutilities, via constructed scales, to the PMs of each of these MGs. All users take on the same constructed scale levels as their respective MG. Figure 6 shows a graphical representation of where the different MGs are located throughout the campus. Note where the MGs group up: Residential in the bottom-left, Academic in the middle to upper-right, Athletic in the middle, and Support littered throughout. The MGs are also summarized in Table 6.

\begin{tabular}{|l|l|l|l|l|}
\hline MG Type & $\begin{array}{l}\text { Number of } \\
\text { users }\end{array}$ & $\begin{array}{l}\text { Total number of people } \\
\text { in MG/Average }\end{array}$ & $\begin{array}{l}\text { Total Floor Space in } \\
\text { MG/Average }\left(\mathrm{ft}^{2}\right)\end{array}$ & $\begin{array}{l}\text { Total Lab Space in } \\
\text { MG/Average }\left(\mathrm{ft}^{2}\right)\end{array}$ \\
\hline A\&R & 68 & $9,800 / 144$ & $3,506,898 / 51,572$ & $1,253,550 / 18,434$ \\
\hline Residential & 26 & $8,350 / 320$ & $1,624,816 / 62,493$ & $2,739 / 105$ \\
\hline Support & 29 & $710 / 24$ & $846,328 / 29,183$ & $30,710 / 1,059$ \\
\hline Athletic & 10 & $850 / 85$ & $340,226 / 34,022$ & $0 / 0$ \\
\hline
\end{tabular}

Table 6: Summary of Macro-User Groups 


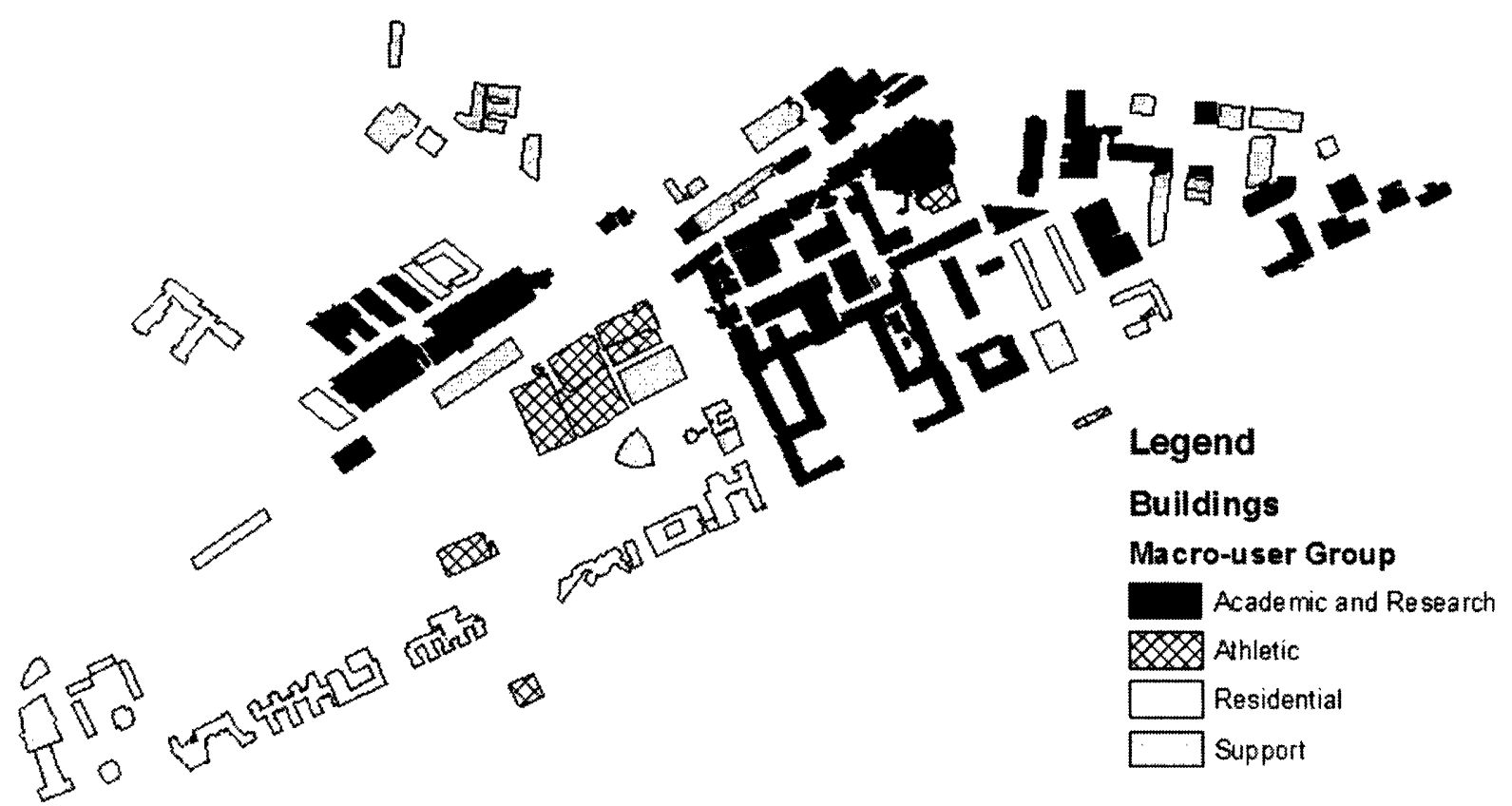

Table 7: Map of Users given by Macro-user Group

We then had to develop constructed scales in order for the decision maker to assess the disutility evoked by events to users. These constructed scales were developed by the DOF at the same time the original value tree was created (Karydas and Gifun, 2002) and were modified by Apostolakis and Lemon (2005). To keep our answers consistent with theirs, we use the same leveling scheme but redefine some of the definitions so they are applicable to all of our MGs. For instance, in our constructed scale for impact of people (Table 5) we have added items like job loss and employment interruption to areas of Apostolakis's and Lemon's constructed scale for impact on people (Table 1). We essentially broadened the scope of impact on people particularly because A\&R as well as support buildings would have been left without a way to assess their employment function. Our redefined constructed scales are presented in Table 5 and Table 8 through Table 14. 


\begin{tabular}{|c|l|c|}
\hline Level & Description & Unweighted \\
& & Disutility \\
\hline 3 & Major Environmental Impact & 1.00 \\
\hline 2 & Moderate Environmental Impact & 0.34 \\
\hline 1 & Minor Environmental Impact & 0.04 \\
\hline 0 & No Environmental Impact & 0.00 \\
\hline
\end{tabular}

Table 8: Constructed Scale for environmental impact

\begin{tabular}{|c|l|c|}
\hline Level & Description & Unweighted \\
Disutility \\
\hline 3 & Catastrophic physical property damage & 1.00 \\
\hline 2 & Major physical property damage & 0.27 \\
\hline 1 & Minor physical property damage & 0.03 \\
\hline 0 & No physical property damage & 0.00 \\
\hline
\end{tabular}

Table 9: Constructed Scale for physical property damage

\begin{tabular}{|c|l|c|}
\hline Level & Description & Unweighted \\
\hline 4 & $\begin{array}{l}\text { Extreme Interruption; Greater than 6 months, entire buildings evacuated } \\
\text { and activities relocated. }\end{array}$ & 1.00 \\
\hline 3 & $\begin{array}{l}\text { Major Interruption; 1 to 6 months, laboratories evacuated and activities } \\
\text { relocated. }\end{array}$ & 0.57 \\
\hline 2 & $\begin{array}{l}\text { Moderate Interruption; 1 to 4 weeks, specialty classrooms evacuated and } \\
\text { activities relocated. }\end{array}$ & 0.19 \\
\hline 1 & $\begin{array}{l}\text { Minor Interruption; Less than 1 week, a few administrative units or small } \\
\text { classrooms evacuated and activities relocated. }\end{array}$ & 0.06 \\
\hline 0 & No Interruption & 0.00 \\
\hline
\end{tabular}

Table 10: Constructed Scale for interruption of academic activities $\&$ operations

\begin{tabular}{|l|l}
\hline Level & Description
\end{tabular}

Unweighted 


\begin{tabular}{|c|l|c|}
\hline & & Disutility \\
\hline 3 & Catastrophic intellectual property damage; Long-term experiments & 1.00 \\
\hline 2 & Major intellectual property damage; Artifacts and rare documents & 0.46 \\
\hline 1 & Minor intellectual property damage; Non-backed up electronic data & 0.05 \\
\hline 0 & No intellectual property damage & 0.00 \\
\hline
\end{tabular}

Table 11: Constructed Scale for intellectual property damage

\begin{tabular}{|c|l|c|}
\hline Level & Description & Unweighted \\
& & Disutility \\
\hline 3 & Major degree of adverse publicity; Petitions, demonstrations & 1.00 \\
\hline 2 & Moderate degree of adverse publicity; Negative articles published & 0.34 \\
\hline 1 & Minor degree of adverse publicity; Verbal complaints & 0.04 \\
\hline 0 & No adverse publicity & 0.00 \\
\hline
\end{tabular}

Table 12: Constructed Scale for internal public image

\begin{tabular}{|c|l|c|}
\hline Level & Description & Unweighted \\
& & Disutility \\
\hline 3 & Major degree of adverse publicity; Affects enrollment, contributions, & 1.00 \\
\hline 2 & Moderate degree of adverse publicity; National/International Media & 0.57 \\
\hline 1 & Minor degree of adverse publicity; Local media & 0.06 \\
\hline 0 & No adverse publicity & 0.00 \\
\hline
\end{tabular}

Table 13: Constructed Scale for external public image 


\begin{tabular}{|c|l|c|}
\hline Level & Description & Unweighted \\
Disutility \\
\hline 4 & Extreme Impact on projects, funding, employment, and students & 1.00 \\
\hline 3 & Major Impact on projects, funding, employment, and students & 0.50 \\
\hline 2 & Moderate Impact on projects, funding, and students & 0.23 \\
\hline 1 & Minor Impact on students & 0.02 \\
\hline 0 & No Impact & 0.00 \\
\hline
\end{tabular}

Table 14: Constructed Scale for programs affected

As we discussed in Section 3.1, to diversify the users even more we added what we called the weighting function. This involved multiplying a natural scale by a constructed scale. Adding this natural scale which is continuous and based on physical data about the users adds another level of distinction between users. These data are attributes already assigned in the GIS database to the buildings. They include the maximum human populations of the buildings, laboratory area, and total usable area of the building. Classroom area was assumed to be usable area minus lab area in academic buildings. These data created a scaling effect on the constructed scales. With these data we added weighting functions to all of the PMs we analyzed with the relation in Table 15.

\begin{tabular}{|l|l|}
\hline Data from GIS & PM for weighting function \\
\hline Max occupancy & People, Programs Affected \\
\hline Lab square footage & $\begin{array}{l}\text { Environment Damage, Intellectual Property, } \\
\text { Programs Affected }\end{array}$ \\
\hline Classroom square footage & Interruption of Academic Activities \\
\hline Usable square footage & Physical Property Damage \\
\hline
\end{tabular}

Table 15: Data and respective PM for weighting function use at MIT 
All of our functions were linear and can be seen in column 2 of Table 16 for each PM. For example, for the PM physical property damage, our weighting function was usable square footage of the user divided by the maximum square footage user. Our largest usable area was $286,527 \mathrm{ft}^{2}$ and an example building A (an A\&R building) had a usable area of $51,979 \mathrm{ft}^{2}$, therefore building A's weighting function value was 0.1814 . This weighting function was multiplied by the picked zoned level for the physical property damage PM for an event. For example, the A\&R loss of a steam resource is expected to cause minor damage to the building (level 1) which corresponds to a disutility $d=0.03$ (Table 9). Therefore, the disutility for the physical property damage PM for building A was $0.03 * 0.1814=0.0054$. Once the disutilities for the other PMs for building A are calculated for the loss of the steam system, the values are added together via Equation (1) to create the total PI for user A for the event of loss of the steam system.

The actual PIs for each user were assessed for each infrastructure loss according to Eq. (1). There are several buildings on campus, e.g., the Research Reactor, that would normally warrant special attention to assess its value or even have its own analysis preformed on it. For our purposes, we try to classify these building into our scheme using the same MG groups, but recognize their importance.

We assessed the constructed scales of each PM for each MG for the loss of each of the five infrastructures independently. We took several samples of user PIs for various infrastructure losses to compare and consistency check them. For example, in Table 16 we present an A\&R building for the loss of gas compared to an Athletic building for the loss of steam. Since we have included weighting functions the users must be checked for consistency in the context of their user data (population, lab area, useable area). Therefore, if we look at the final PI, we see that they are very close, thus suggesting that we should be almost indifferent between the two different events (one user for gas loss and the other for steam loss) to the respective users in the context of not only their MG, but also the size of the building, people in the building, and lab 
space in the building. We also showed these consistency checks to an individual whom was present at the original MIT DOF stakeholder deliberations.

Figure 6 compares all users grouped by the 4 MG PIs for all five events (loss of each infrastructure) (note the PI is cumulative for all events). It is notable in Figure 6 how the MG hierarchy via picking different constructed scales created diversity between each MG based for a given event. The weighting function then diversified each user within an MG based on the GIS data.

\begin{tabular}{|l|l|}
\hline \multicolumn{2}{|c|}{ User Data } \\
\hline \multicolumn{2}{|c|}{ User $a$} \\
MG: Athletic & MG: A\&R \\
Event: Steam Loss & Event: Steam Loss \\
Population: 42 & Population: 220 \\
Lab Area $\left(\mathrm{ft}^{2}\right): 0$ & Lab Area $\left(\mathrm{ft}^{2}\right): 57685$ \\
Useable Area $\left(\mathrm{ft}^{2}\right): 16613$ & Useable Area $\left(\mathrm{ft}^{2}\right): 66069$ \\
\hline
\end{tabular}

\begin{tabular}{|c|c|c|c|c|}
\hline \multirow{2}{*}{$\begin{array}{c}\text { PMs } \\
\text { (weight (w)) }\end{array}$} & \multirow{2}{*}{$\begin{array}{c}\text { Weighting Function for } \\
\text { PM }\end{array}$} & \multirow{2}{*}{$\begin{array}{c}\text { Disutility } \\
\text { Calculations }\end{array}$} & \multicolumn{2}{|c|}{ User } \\
\hline & & & User $a$ & User $b$ \\
\hline \multirow{4}{*}{$\begin{array}{c}\text { Impact on } \\
\text { People } \\
(0.295)\end{array}$} & \multirow{4}{*}{$\frac{\text { User_Population }}{1200}$} & Zoned Level & 1 & 1 \\
\hline & & $\begin{array}{c}\text { Unweighted } \\
\text { Disutility }\end{array}$ & 0.05 & 0.05 \\
\hline & & $\begin{array}{c}\text { Weighting } \\
\text { Function Value }\end{array}$ & 0.03461 & 0.18352 \\
\hline & & $\begin{array}{c}\text { Weighted } \\
\text { Disutility (d) }\end{array}$ & 0.00173 & 0.00918 \\
\hline \multirow{4}{*}{$\begin{array}{c}\text { Impact on } \\
\text { Environment } \\
(\mathbf{0 . 1 9 6 )}\end{array}$} & \multirow{4}{*}{$\frac{L a b \_ \text {Area }}{119012}$} & Zoned Level & 0 & 1 \\
\hline & & $\begin{array}{l}\text { Unweighted } \\
\text { Disutility }\end{array}$ & 0 & 0.04 \\
\hline & & $\begin{array}{c}\text { Weighting } \\
\text { Function Value }\end{array}$ & 0 & 0.835869 \\
\hline & & Weighted & 0 & .0334 \\
\hline
\end{tabular}




\begin{tabular}{|c|c|c|c|c|}
\hline & & Disutility (d) & & \\
\hline \multirow{4}{*}{$\begin{array}{c}\text { Physical } \\
\text { Property } \\
\text { Damage } \\
(0.049)\end{array}$} & \multirow{4}{*}{$\frac{\text { Useable_Area }_{286726}}{2867}$} & Zoned Level & 0 & 1 \\
\hline & & $\begin{array}{l}\text { Unweighted } \\
\text { Disutility }\end{array}$ & 0 & 0.03 \\
\hline & & $\begin{array}{c}\text { Weighting } \\
\text { Function Value }\end{array}$ & 0 & 0.230586 \\
\hline & & $\begin{array}{c}\text { Weighted } \\
\text { Disutility (d) }\end{array}$ & $\mathbf{0}$ & .00692 \\
\hline \multirow{4}{*}{$\begin{array}{c}\text { Impact on } \\
\text { Academic } \\
\text { Programs and } \\
\text { Operations } \\
(0.056)\end{array}$} & \multirow{4}{*}{$1-\frac{\text { Lab_Area }}{119012}$} & Zoned Level & 0 & 1 \\
\hline & & $\begin{array}{l}\text { Unweighted } \\
\text { Disutility }\end{array}$ & 0 & 0.06 \\
\hline & & $\begin{array}{c}\text { Weighting } \\
\text { Function Value }\end{array}$ & 0 & 0.1461 \\
\hline & & $\begin{array}{c}\text { Weighted } \\
\text { Disutility (d) }\end{array}$ & 0 & .008766 \\
\hline \multirow{4}{*}{$\begin{array}{c}\text { Intellectual } \\
\text { Property } \\
\text { Damage } \\
(0.128)\end{array}$} & \multirow{4}{*}{$\frac{\text { Lab_Area }}{\text { Useable_Area }}$} & Zoned Level & 0 & 1 \\
\hline & & $\begin{array}{c}\text { Unweighted } \\
\text { Disutility }\end{array}$ & 0 & 0.05 \\
\hline & & $\begin{array}{c}\text { Weighting } \\
\text { Function Value }\end{array}$ & 0 & 0.873102 \\
\hline & & $\begin{array}{c}\text { Weighted } \\
\text { Disutility (d) }\end{array}$ & $\mathbf{0}$ & .04366 \\
\hline \multirow{4}{*}{$\begin{array}{c}\text { Impact on } \\
\text { External } \\
\text { Image } \\
(0.083)\end{array}$} & \multirow{4}{*}{ N/A } & Zoned Level & 1 & 1 \\
\hline & & $\begin{array}{l}\text { Unweighted } \\
\text { Disutility }\end{array}$ & 0.06 & 0.06 \\
\hline & & $\begin{array}{c}\text { Weighting } \\
\text { Function Value }\end{array}$ & N/A & N/A \\
\hline & & $\begin{array}{c}\text { Weighted } \\
\text { Disutility (d) }\end{array}$ & 0.06 & 0.06 \\
\hline \multirow{3}{*}{$\begin{array}{c}\text { Impact on } \\
\text { Internal } \\
\text { Image } \\
(0.055)\end{array}$} & \multirow[t]{3}{*}{ N/A } & Zoned Level & 2 & 1 \\
\hline & & $\begin{array}{l}\text { Unweighted } \\
\text { Disutility }\end{array}$ & 0.34 & 0.04 \\
\hline & & & & \\
\hline
\end{tabular}




\begin{tabular}{|c|c|c|c|c|}
\hline & & Function Value & & \\
\hline & & $\begin{array}{c}\text { Weighted } \\
\text { Disutility (d) }\end{array}$ & 0.34 & 0.04 \\
\hline \multirow{4}{*}{$\begin{array}{c}\text { Programs } \\
\text { Affected } \\
(\mathbf{0 . 1 3 8 )}\end{array}$} & \multirow{4}{*}{$\frac{\left(\frac{\text { Lab_Area }}{119012}+\frac{\text { Population }}{1200}\right)}{2}$} & Zoned Level & 1 & 1 \\
\hline & & $\begin{array}{c}\text { Unweighted } \\
\text { Disutility }\end{array}$ & 0.02 & 0.02 \\
\hline & & $\begin{array}{c}\text { Weighting } \\
\text { Function Value }\end{array}$ & 0.017305 & 0.509697 \\
\hline & & $\begin{array}{c}\text { Weighted } \\
\text { Disutility (d) }\end{array}$ & 0.000346 & 0.01019 \\
\hline & USER PI & & 0.024238 & 0.024325 \\
\hline
\end{tabular}

Table 16: Example of a user consistency check

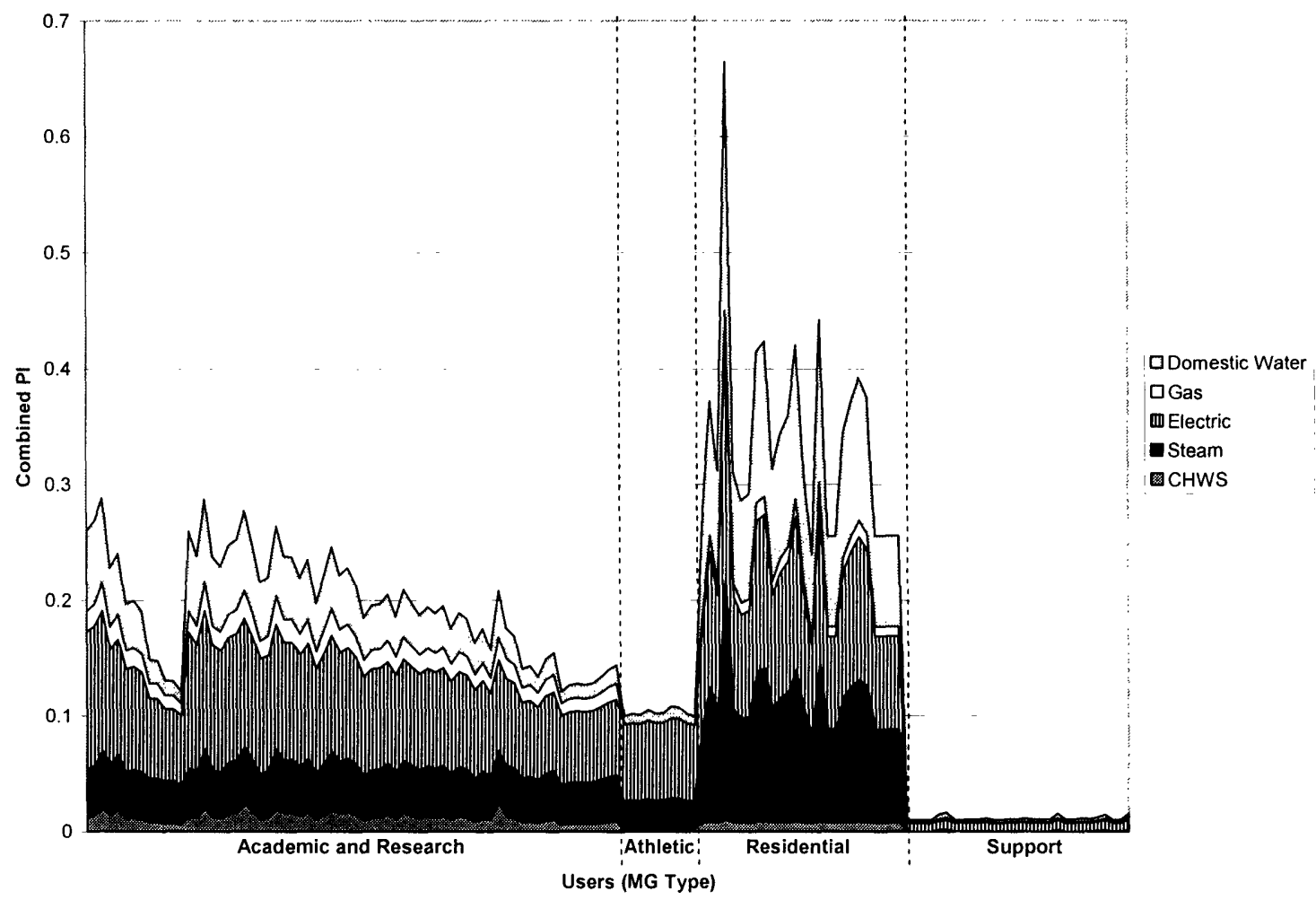

Figure 6: All users grouped by MG for comparison for all events. The PI on the y-axis is cumulative; each event's PI is added to the others. To get an individual event's PI for a user take look at only the height portion the respective shaded area covers. 
The following are some major trends in the resulting PIs: 1) All A\&R users have high PI for electric power loss; 2) the more classroom percent space in an A\&R user, the closer the PI for electric power loss and steam loss get, i.e., heating is relatively more important to classrooms than labs; 3) Residential MG users' highest PI vary among domestic water, steam, and electric loss; 4) Resident users are relatively close in their PI for domestic water, steam, and electric power loss, resident buildings with computer labs have a high PI for electric power loss; 5) Support buildings have the highest PI for electric power loss; 6) Athletic buildings have the highest PI for electric power loss; 7) The large spikes in the residential MGs are caused by the most populated building on campus; 8) Support buildings do not evoke much disutility for all events mainly due to the small size of the buildings and the low population of people in them; 9) Athletic users are the second lowest group due to the inability to cause disutility for events to many of the PMs, e.g., academic operations, intellectual property, etc..

The calculated PIs just developed for each of the five events (loss of electric, domestic water, natural gas, steam, and chilled water) were inputted into the GIS database for each user; i.e. each user has five PIs, one for each event. We then performed the network analysis on each infrastructure.

\subsection{Network Analysis}

A Monte Carlo network analysis was performed in accordance with the methodology covered previously. The first step in simulation is to first pick our probability of a successful attack. We chose a low number $(0.01)$. With this number set, we had to simulate enough trials to make our results reliable. To make what we considered a reliable simulation, we took relative variance of a random test element for each users simulations (Billington, 1992). We chose a 5\% relative variance ${ }^{*}$ as our goal. The test element was chosen randomly for each infrastructure and

\footnotetext{
" Relative variance is a technique used in Monte Carlo methods to reduce the error of the results. It helps determine a sufficient sample size required to increase confidence in the simulation results.
} 
was based on the RAW importance measure value. Simulations of 20,000 trials were not consistently under 0.05 relative variance. However when we ran 30,000 random system states for each user where all elements had a $1 \%$ chance of a successful attack, we got a relative variance under $5 \%$ for the test element. Thus 30,000 simulations with a $1 \%$ change of a successful attack were our Monte Carlo simulation parameters. With the parameters set we began the simulations. The program chose random numbers to simulate the 30,000 states for each user. We

tracked the $U_{\text {total }}, U_{\text {system-fail }}, U_{k \text {-fail, }}, U_{k-\text { fail-system-fail, }} U_{k \text {-working, }} U_{k-\text { working-system-fail }}$ counters until the user/infrastructure combination and created the worth for each element according to Equation (10). Once all users for one infrastructure were simulated we calculated the valued worth for all of the current infrastructure's elements according to Equation (11).

\subsection{Individual Infrastructure Results}

Before we move on to show the GVW, we will look at the resultant VW's of each infrastructure individually.

\subsubsection{Chilled Water System}

The VW shown in Figure 7 is for the chilled water system (CHWS) using RAW. 


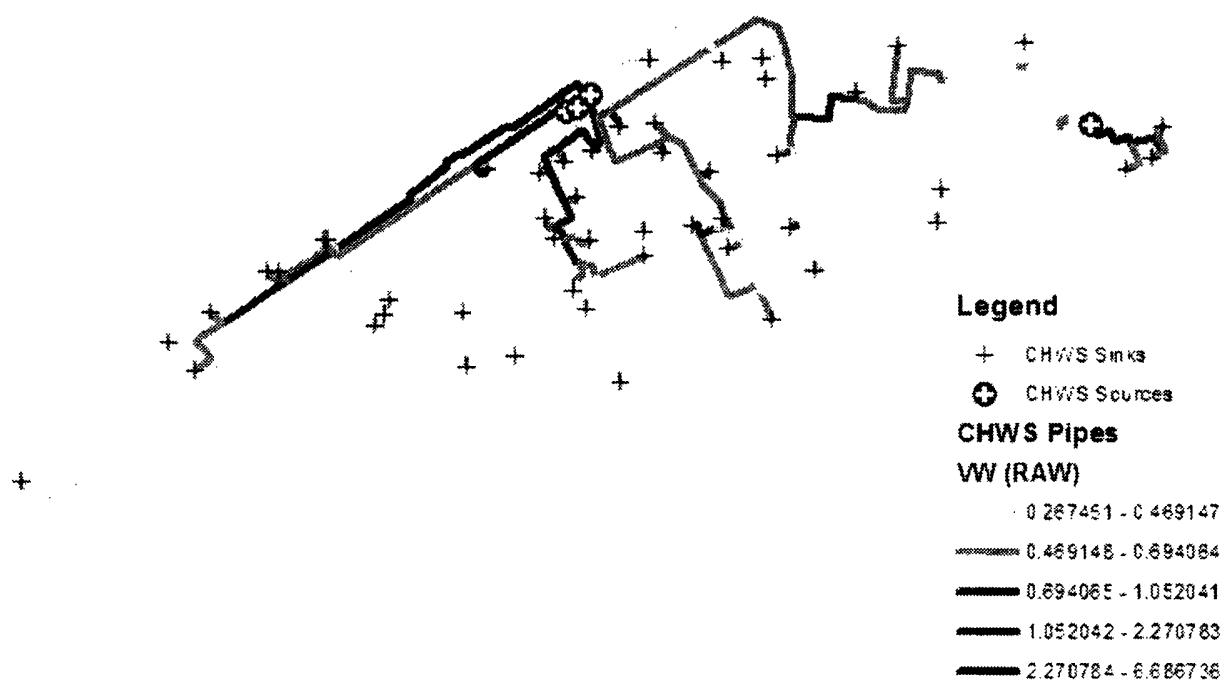

Figure 7: Chilled Water System VW using RAW

Looking at Figure 7's network layout and where the supplies and users are located, we can check our results. The highest VW areas are pipes entering the Central Utility Plant, which, aside from a minor plant to the right, is the only production source of chilled water on campus. The higher areas in general surround the academic buildings, if we look at Figure 6 we see that A\&R users have the highest PI for CHWS loss and thus created higher VW. There are some redundant loops which lower the VW in the middle of the campus. However for the most part this system is mostly in series and filters through very few pipes coming out of the CUP.

The number set of the VWs is $0.267451-6.686736$ which is relatively low when compared to the other infrastructures. Despite the system's lack of redundancy, the loss of CHWS to its users does not cause much disutility to them. Thus we would expect a relatively low number set.

\subsubsection{Electric Power System}

The VW shown in Figure 8 is for the electric power system using RAW. 


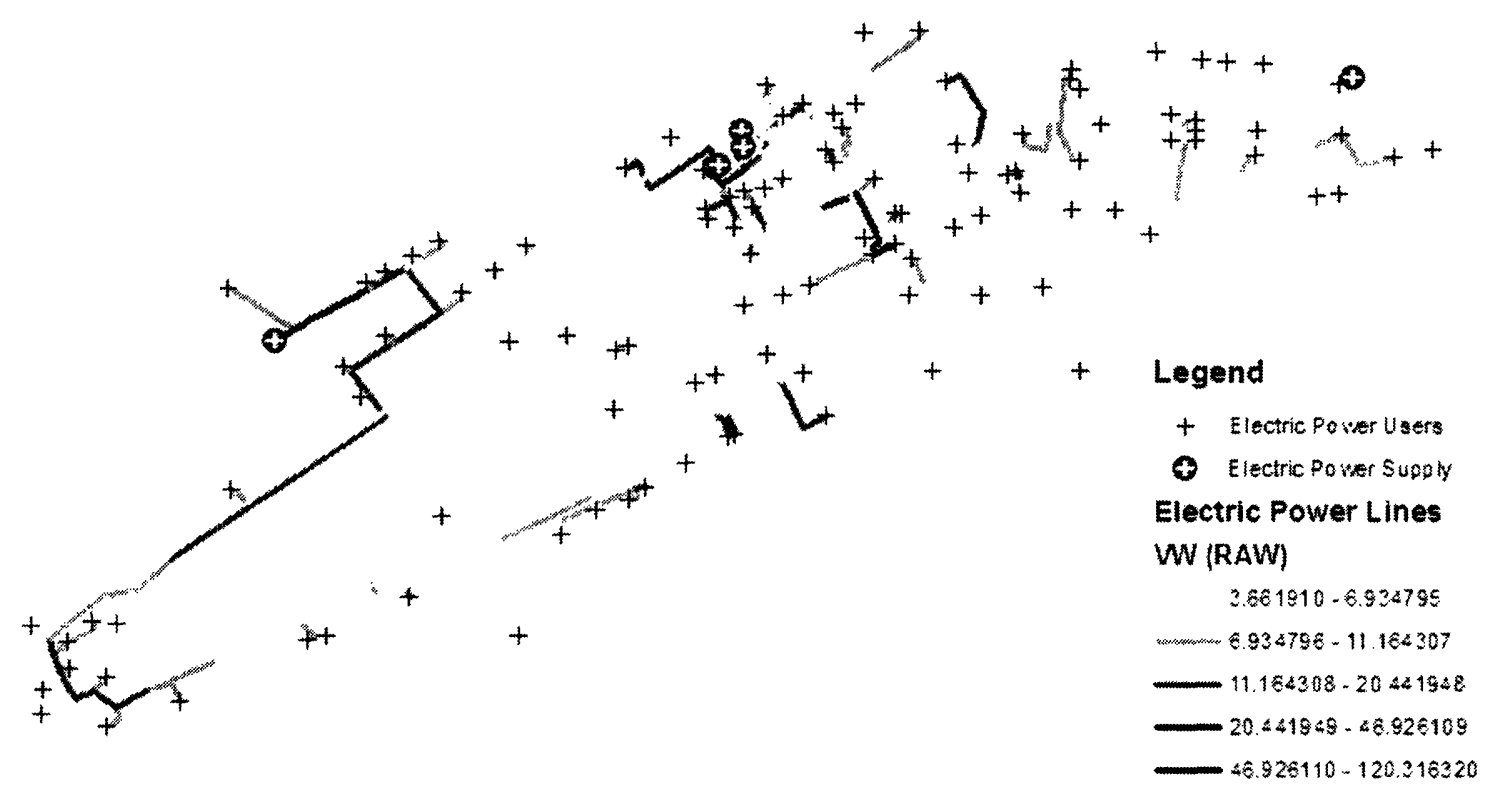

Figure 8: Electric Power System VW using RAW

We check our results again. We see that our highest valued lines are coming out of the CUP or are located toward the left side of campus. The left side supplies the residential users and is therefore more important than some of the other areas. However, we really need to consider the VW number range of the electric power system. The number set of the valued worths is $3.661910-120.316320$, which contains the highest values when compared to the other infrastructures. All users rely heavily on the electric power system. This system, despite its four separate loops, is not very redundant along its loops.

The number range suggests that losing our least valued electric power line is almost as important to us as our top natural gas lines (see next section). It also shows that the majority of the lines are more important than most all of the CHWS pipes, all of the natural gas pipes, most of the steam pipes, and most of the DOMW pipes. Thus, despite the relative ranking of the electric power lines being higher or lower than one another, when the GVW is found in the next section, these "low ranked" lines will prove to create high GVW areas for the whole campus. Therefore, the results for the electric power system should prove to dictate much of the GVW. 


\subsubsection{Natural Gas System}

The VW shown in Figure 9 is for the natural gas system using RAW.

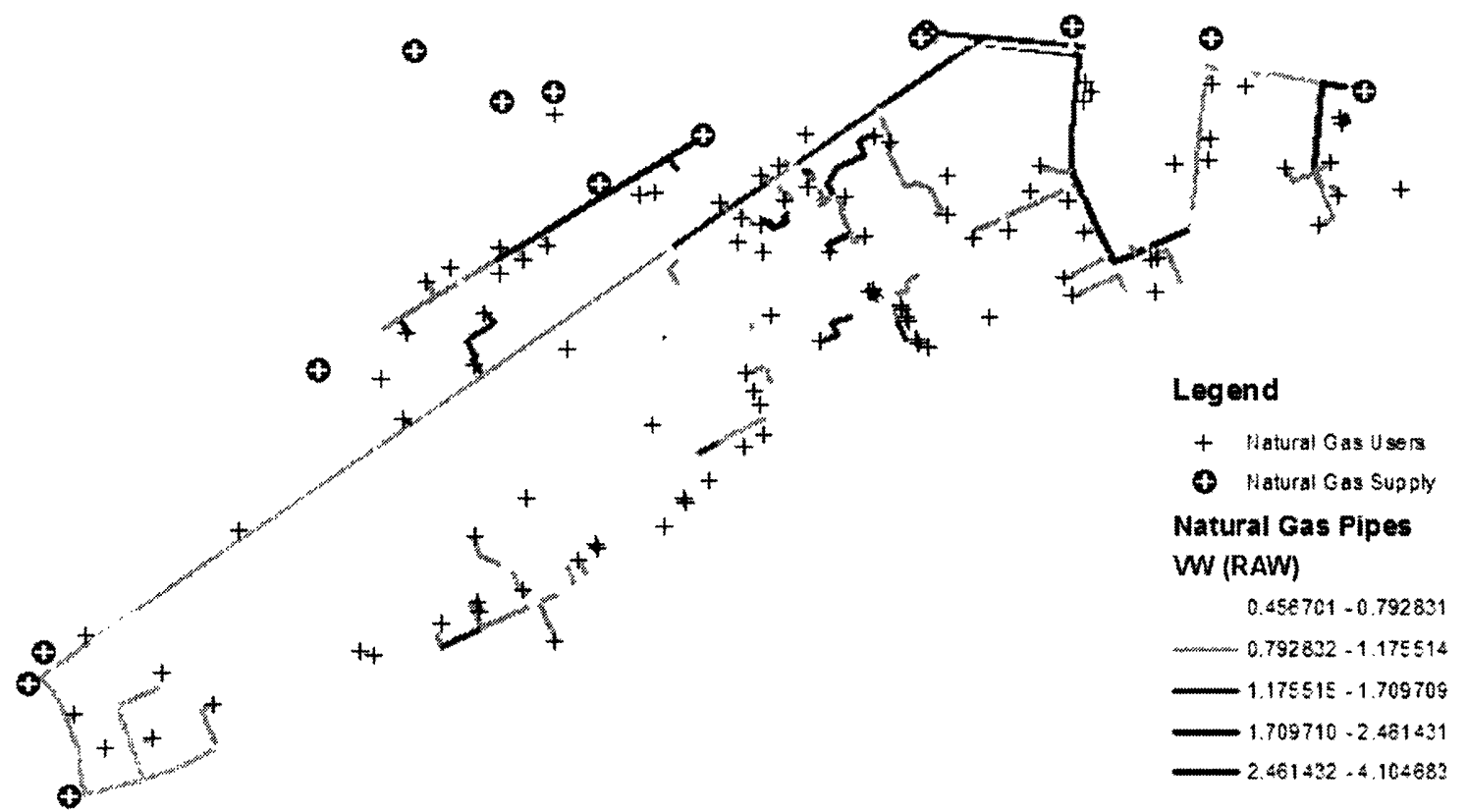

Figure 9: Natural Gas System VW using RAW

We check our results again. This system has the most supplies and therefore a lot of redundancy. This causes a lack of a concentration of high VW areas. Individually, the A\&R and residential users tend to rely on natural gas equally. However, there are over twice the number of A\&R uses as residential so the higher valued areas tend to center around the concentration of A\&R users in the main campus (center to right of the map).

The number rank of the valued worths is $0.456701-4.104683$, which is relatively low when compared to the other infrastructures. Again, looking at Figure 6, we note that there is not much disutility caused by the natural gas so we would expect lower values. The values are even lower than the CHWS due to the CHWS centralized supply area.

\subsubsection{Domestic Water System}


The VW shown in Figure 10 is for the domestic water system (DOMW) using RAW.

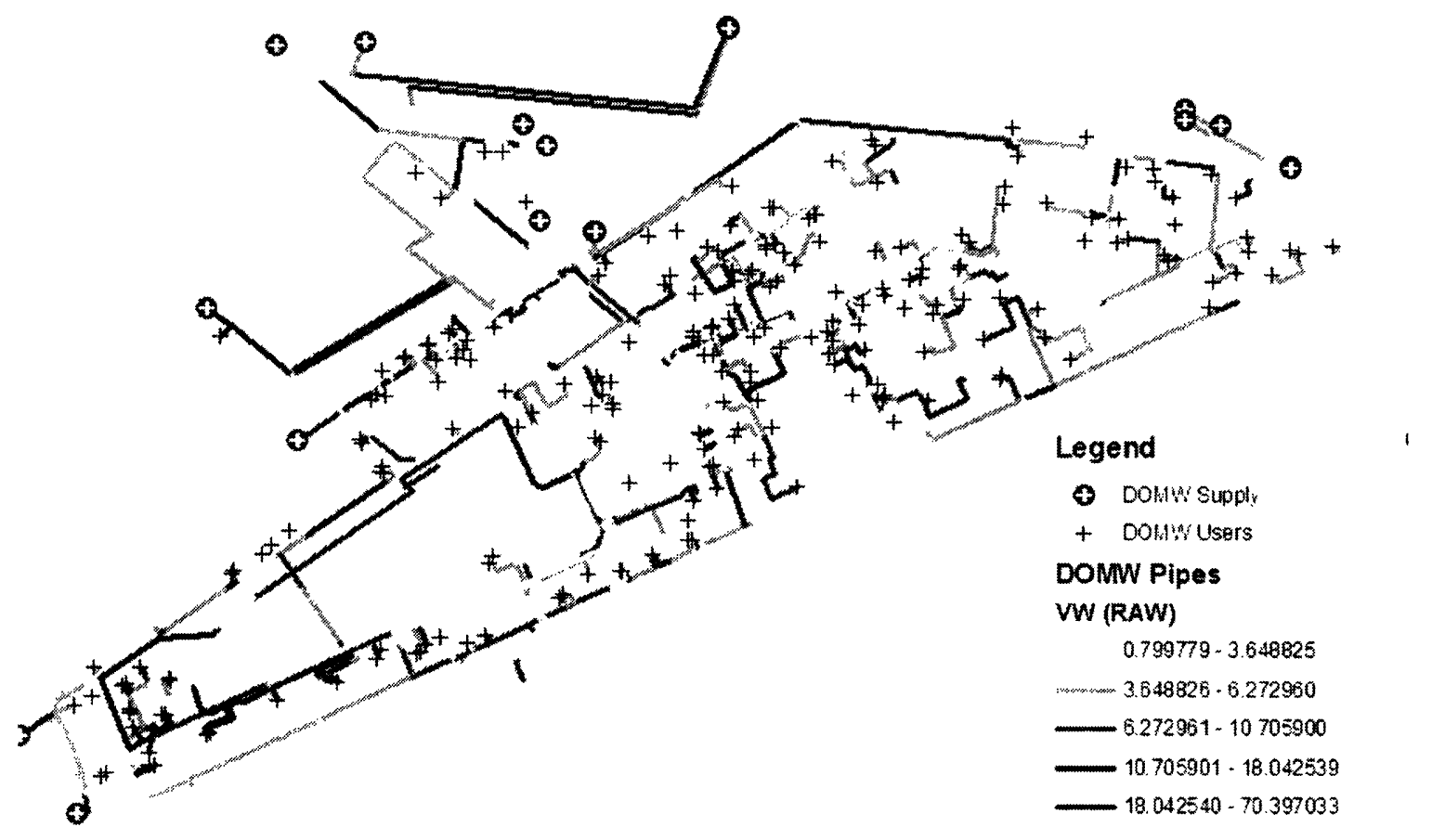

Figure 10: Domestic Water System VW using RAW

Like the natural gas infrastructure, we have many different supplies from off campus feeding our users. The large mains have redundant connections to each other. However, once the network draws away from the main lines, there are many series connections. Yet, since these connections do not serve as many users as the main supply pipes, we find that the highest areas are the pipes near the supplies.

The large dependence of residential users on DOMW creates high VW in the lower left of our map. We can also note that the dinning areas (residential MG) on campus have high VW pipes servicing them due to their reliance on DOMW to feed the campus.

There is also a concentration in the main A\&R buildings (dead center of the map) which have numerous classrooms and therefore numerous people are located in these areas. Thus, they have a high reliance on DOMW particularly for the bathrooms.

The number set of the valued worths is $0.299779-70.397033$, which is relatively high when compared to the other infrastructures. Again, looking at Figure 6 we note that there is a lot 
disutility caused particularly by the residential users. The extra redundancy particularly in the middle of the campus creates VW numbers that are on par with some of the CHWS and natural gas pipes. This is the most redundant system.

\subsubsection{Steam System}

The VW shown in Figure 11 is for the steam system using RAW.

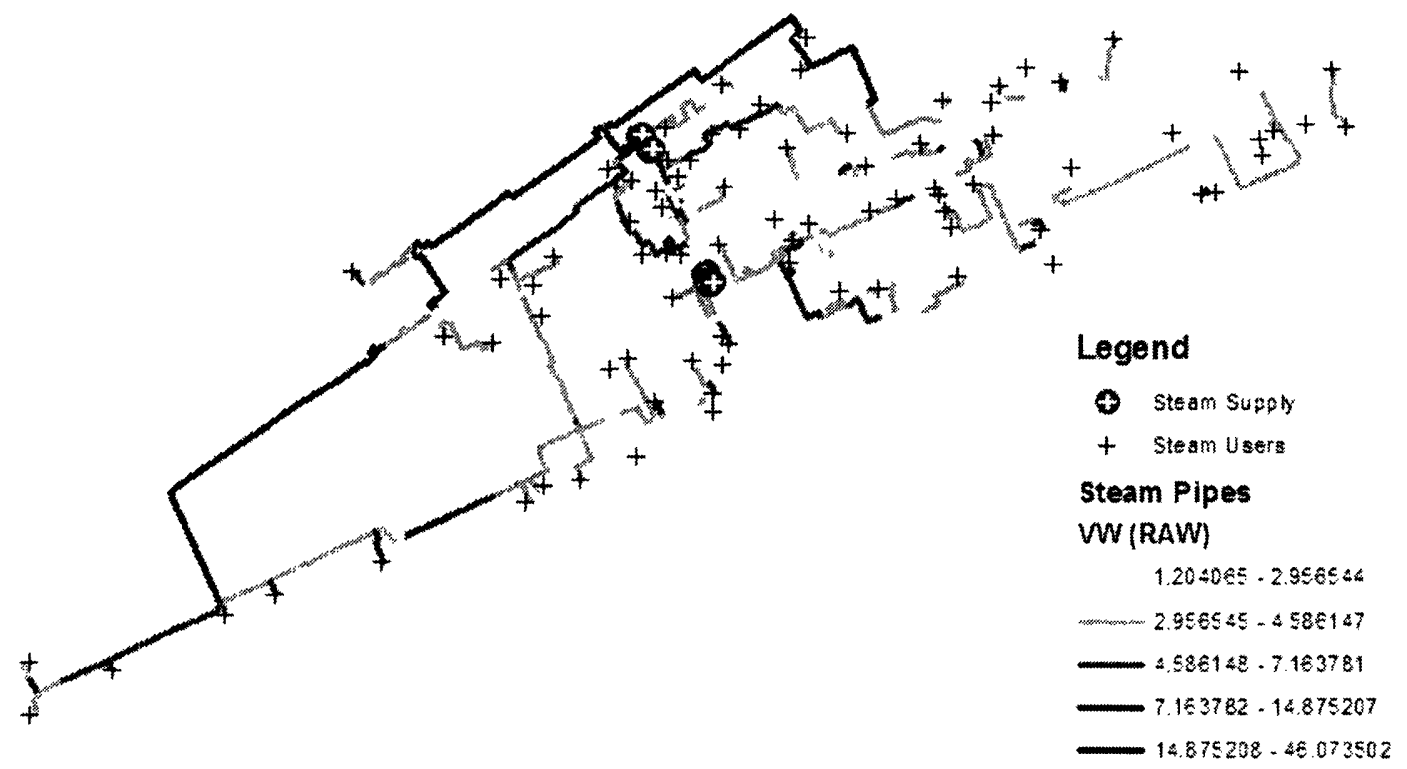

Figure 11: Steam System VW using RAW

Like the CHWS, the steam system is an on-campus utility. Therefore, we find a concentration of high VW pipes around the Central Utilitys Plant. But the loss of steam can cause high disutility to the residential users on the left side of campus so much of the high VW pipes are locate more to the left side. The left side of the campus is also not very redundant.

We can see that the upper supply out of the CUP is higher VW than the lower since the lower and eastern users on campus are more redundantly supplied by a second steam plant just below the CUP, almost in the center of the map. 
The number set of the valued worths is $1.1204065-46.073502$, which is the middle infrastructure as far as the VW are concerned. But 46 is a high VW which is due to the large dependence of the residential users and some A\&R users on steam while also being less redundant to the residential users. We can see that the lowest values of the steam system are not as low as, for example the DOMW system, due to the lack of redundancy in the system.

\subsection{Geographic Valued Worth}

As explained in the methodology section, we must pick a threat that our GVW can be conditional upon. We have chosen a bomb that can destroy everything in a 7-meter radius. This 7-meter radius is our radius of influence and all GVW results will be conditional on it. To develop the GVW a grid of hexagons with the height and width of two times our radius of influence was developed and the GVW was calculated. This result is in Figure 12.

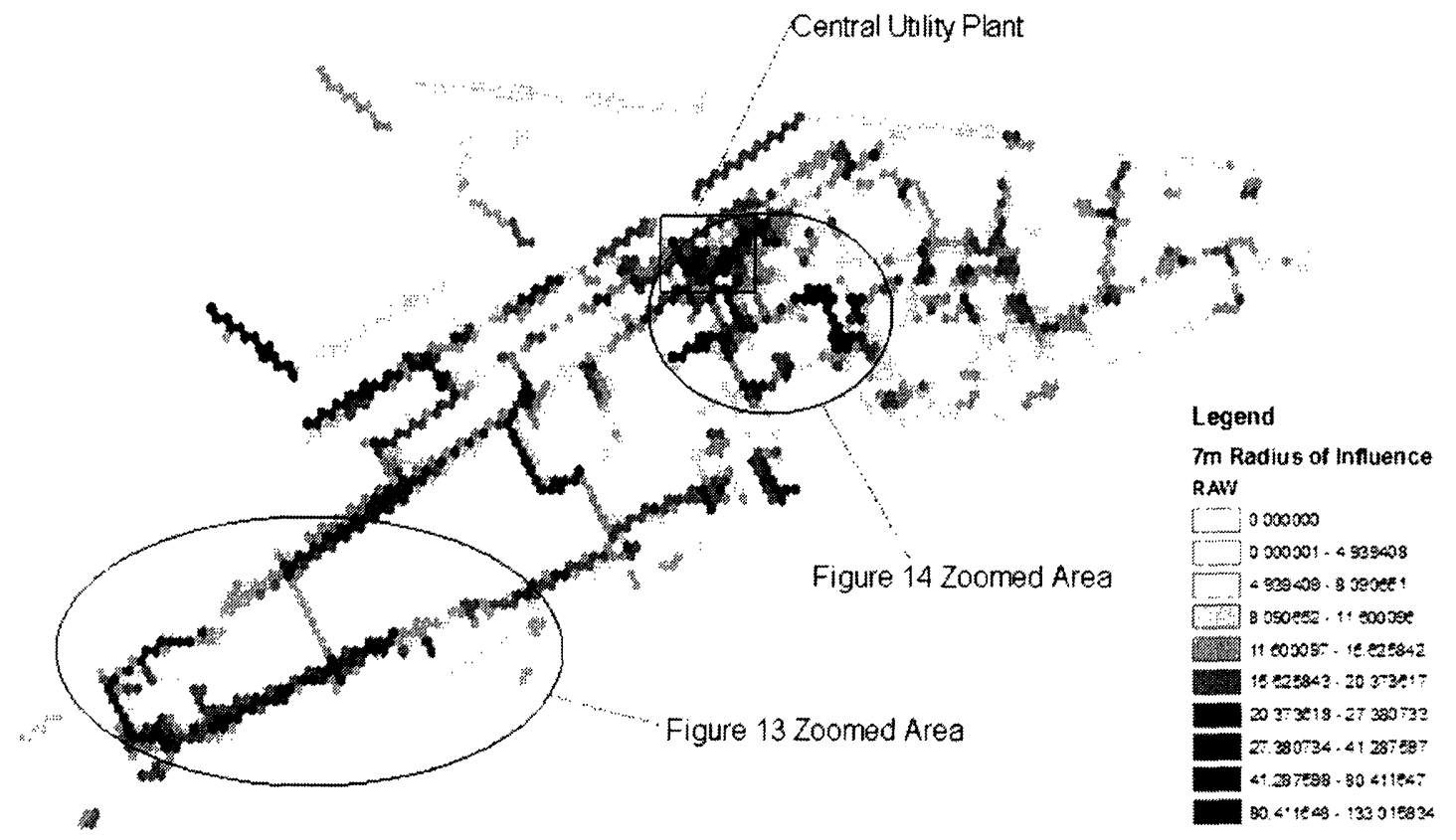

Figure 12: GVW Conditional Risk Map using RAW for the MIT campus

The highest GVWs are located near the Central Utility Plant, which makes sense since the CUP produces $80 \%$ of the electricity, all of the steam, and all of the chilled water for the 
campus. This means the immediate areas just outside of the plant are of great importance to the campus. We note that the high GVW values follow much of the electric power system, which makes sense since it causes the highest disutility to most users.

There is a high GVW "loop" that services the residential users in the bottom left of the campus. If we zoom in (Figure 13) on this area, we see that there are pipes for electric power, steam, water, and natural gas that all run under the same streets very close to each other, many times within the radius of influence, till they service the dorms in the left campus. These long stretches are not very redundant.

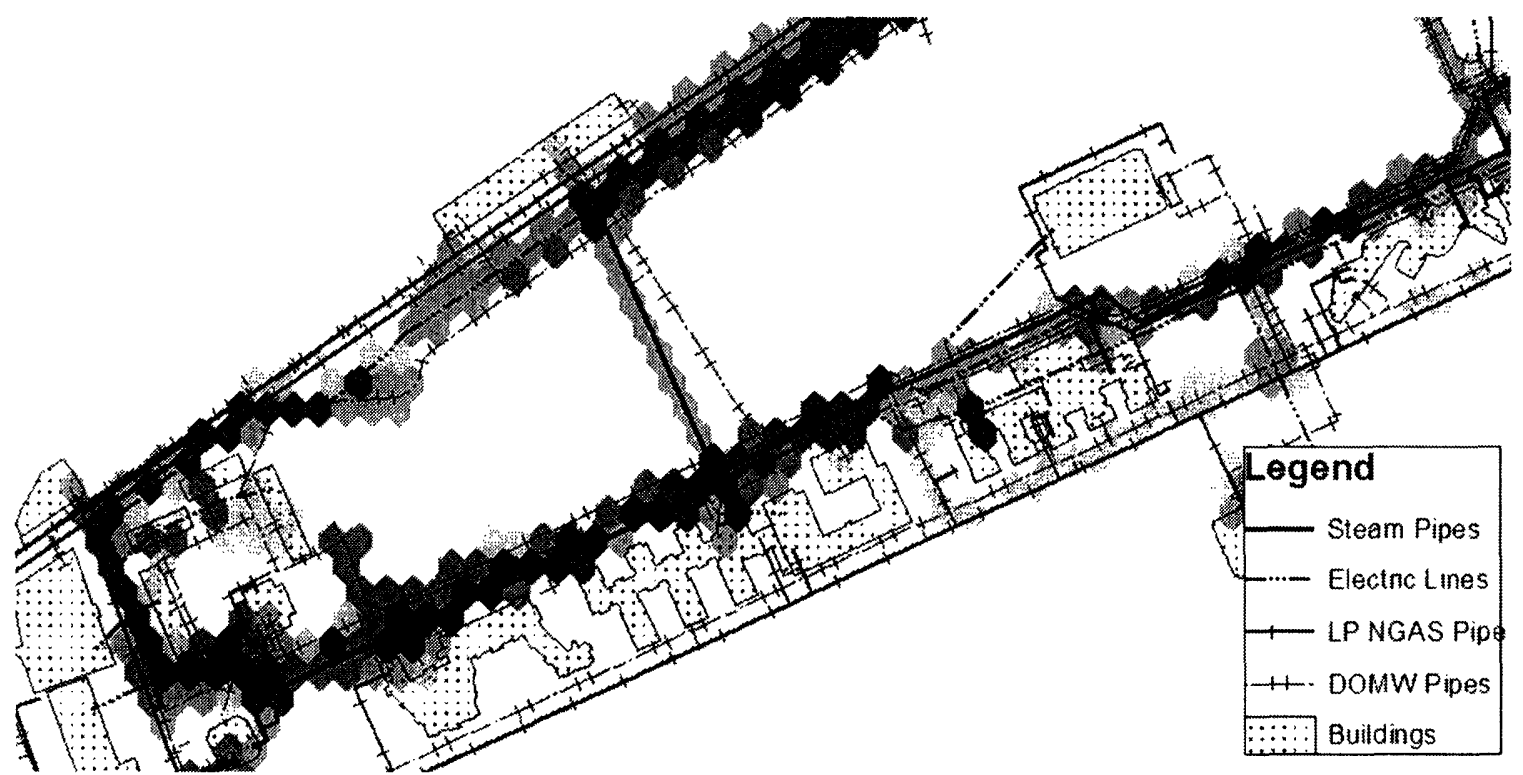

Figure 13: Zoom in on left size of campus. GVW in the background.

We also note the high GVW area in the left side and middle of campus. This is caused by the high VW of the DOMW system, which services a major dorm and a few major A\&R buildings without much redundancy.

Also in the middle of campus we see two areas below and to the left and right of the CUP (Figure 14). All five infrastructures pass though these areas to service the left and right sides of campus. Therefore, these two areas are two low-redundancy bottle necks, or choke points, on the campus. 


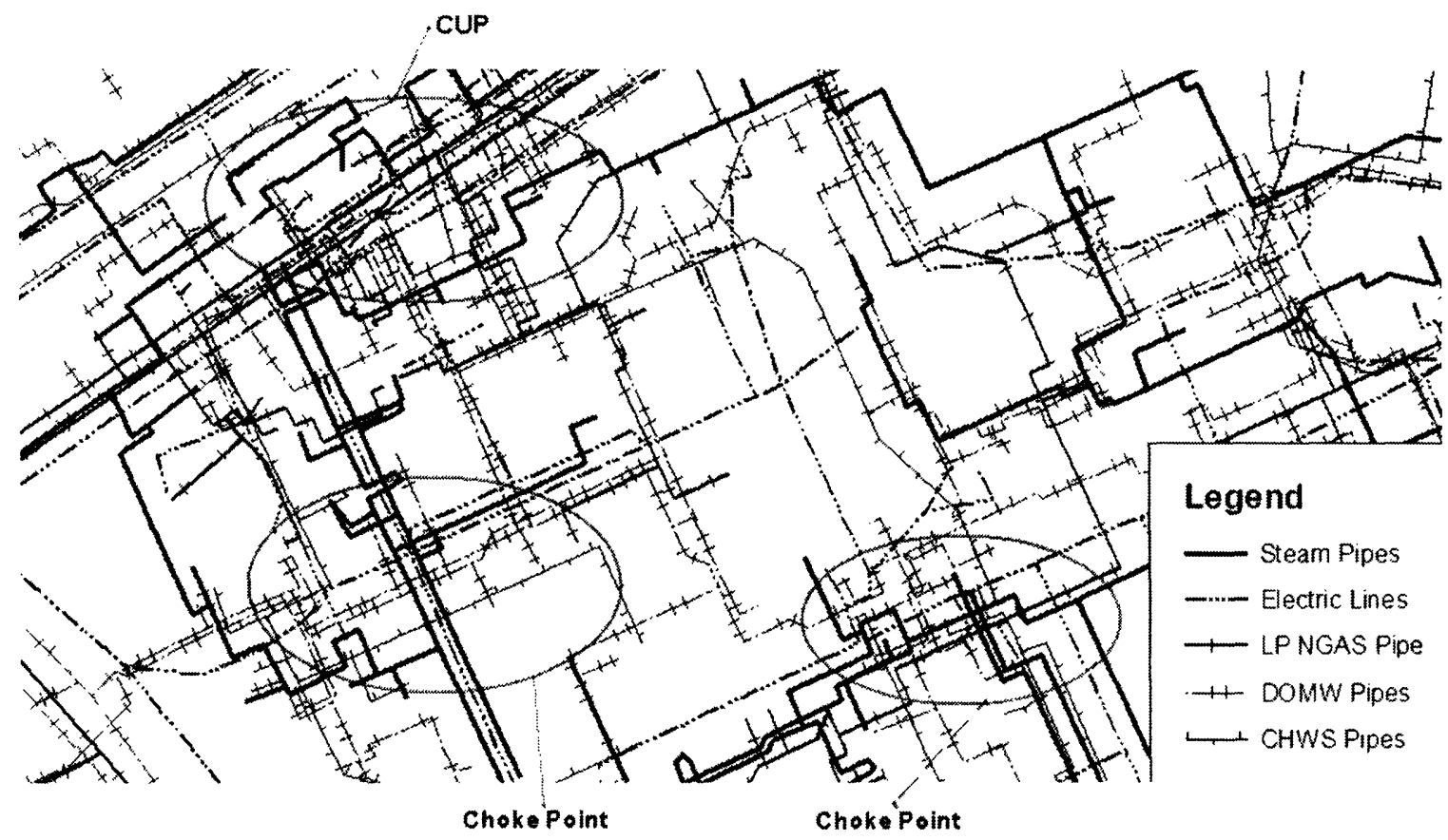

Figure 14: Zoom in around CUP and two choke points in center of campus. No GVW displayed.

We see that the proximity of infrastructures within a radius of influence leads to larger GVW values, as it should. The proximity of the electric system to the steam or domestic water system in the left campus creates the highest GVW areas. The proximity of steam and DOMW pipes in the left campus can create areas more risky than the highest electric power areas when considered independently. Gas and CHWS do not affect the GVW too much since their additions do not raise the GVW high enough to compete with the high values where the DOMW, electric, or steam systems are collocated. However, they can influence middle ranked pipes of the DOMW, electric, or steam to move the area up in GVW rank enough to become a notable GVW area.

We must remember that by using importance measures the solution we are giving is not like that in a minimal-cut-set analysis. We cannot say that the highest valued worth (geographic or infrastructure element) will for sure cause a failure to its connected users. Rather, we determine that the higher the GVW the more the unavailability of the elements passing through it 
the closer the systems are to failure with a certain amount of disutility. The elements in the area may or may not cause directly a resource loss to the respective users.

\section{Input to Decision Makers}

The conditional risk maps are given to decision makers to decide the susceptibility of the areas to attack. Since all of our infrastructures have the same failure probability, the decision makers must make these susceptibility decisions. In time, we could apply susceptibility before the GVW analysis by changing the probabilities of failure. We could for instance add a program which would determine the probability of failure of an element conditional on the threat, e.g., the amount of TNT a bomb has, and how the element is located, e.g., buried under concrete vs. under soil. GIS has the capability of doing 3D analysis, therefore we could affect underground lines and above-ground lines of varying heights and depths differently. If an area were determined to be of high GVW and high susceptibility by the decision makers, then it should be considered a critical location of the entire system, i.e., for all infrastructures and users. The GVW is most important to the decision makers because it is a global metric that represents the worth (to the decision makers) of a location across all infrastructures. The GVW does not care about the infrastructures individually, only the result of combining all infrastructures. In a singleinfrastructure analysis, we find elements of significant risk for that particular infrastructure, like our VW results. If we were allocating resources to protect that infrastructure only, we would

apply the resources to those high-risk elements. However, in a terrorist scenario we are trying to protect society and what society (i.e., the decision makers) deems important. Therefore, our multi- infrastructure analysis and the GVWs prioritize areas that are important to society so that resources can be allocated accordingly.

The highest risk areas of two infrastructures, when analyzed separately, are in general different from those that are found when these infrastructures are analyzed together, as we did in this paper. 


\section{Conclusions}

The methodology we have presented takes the results of stakeholder deliberations about the performance measures that the stakeholders deem important to society and converts their values through network and spatial analysis to a ranking of geographic areas that can adversely disturb the infrastructure services to the stakeholders. It accomplishes this by first determining a valued worth of each of the elements of the infrastructures networks. This valued worth is based on the characteristics of the users (PIs) and the importance measures of the elements which make up the infrastructures which supply resources to those users. The methodology then assesses the geographic valued worth of physical areas of defined size (based on the radius of influence) by determining combining the values of all the infrastructure elements within the physical area. The

result is a ranking of physical areas that can be expressed in a graphical form on a map. This map aids decision makers in the allocation of countermeasures to better protect society from malicious threats.

We note that we have made some broad assumptions (user independence, PM independence, failure probabilities) in several areas, however, with expert opinion the assumptions could be limited to provide a realistic analysis of the infrastructures. Despite the assumptions in our case study, we believe this method of developing GVW across multiple infrastructures for terrorism is of importance to decision makers for anti-terrorism resource allocation. The process we have presented effectively draws attention to the geographic areas that merit attention by the decision makers. Had we only relied on the analysis of the infrastructures individually, we might not have noticed that a geographic location, which may be of moderate importance to the networks independently, is of extremely high importance if all infrastructures are considered. 


\section{References}

Apostolakis, G.E., and Lemon, D.M., 2005. "A Screening Methodology for the Identification and Ranking of Infrastructure Vulnerabilities due to Terrorism," Risk Analysis, 25:361-376.

Billinton, R., 1992. Reliability Evaluation of Engineering Systems: Concepts and Techniques. New York : Plenum Press.

Cheok, M.C., Parry, G.W., and Sherry, R.R..,1997. "Use of importance measures in riskinformed regulatory applications" Reliability Engineering and System Safety, 60: 213-226.

Clemen, R. T., 1996. Making Hard Decisions: An Introduction to Decision Analysis. $2^{\text {nd }}$ Edition. Belmont, CA, Duxbury Press.

Garrick, B.J., J.E. Hall, M.Kilger, J.C.McDonald, J.C. McGroddy, T.O’Toole, P.S. Probost, E. Rindskopf Parker, R. Rosenthal, A.W. Trivelpiece, L. Van Arsdale, and E. Zebroski, 2004. "Confronting the Risks of Terrorism: Making the Right Decisions," Reliability Engineering and System Safety, 86:129-176.

Gregory, R., and Keeney, R. L., 1995. "Creating policy alternatives using stakeholder values." Management Science, 40:1035-1048.

Haimes, Y.Y., Horowitz, B.M., 2004. "Modeling interdependent infrastructures for sustainable counterterrorism." Journal of Infrastructure Systems, 10, 33-42.

Karydas, D.M., and Gifun, J.F. 2002. "A Methodology for the Efficient Prioritization of Infrastructure Renewal Projects." Proceedings of the $6^{\text {th }}$ International Conference on Probabilistic Safety Assessment and Management (PSAM 6), San Juan, Puerto Rico, 2328 June 2002, Editor: E.J. Bonano, Elsevier Science Ltd., United Kingdom.

Marseguerra, M. and E. Zio, 2002. Basics of Monte Carlo Method with Application to System Reliability. Hagen, Germany: LiLoLe-Verlag.

Michaud, D., and Apostolakis, G.E., 2005. "Screening Vulnerabilities in Water-Supply Networks.” In preparation. 
National Research Council, 2002. Making the Nation Safer, National Academy Press, Washington, DC.

Office of Homeland Security, 2002. National Strategy for Homeland Security, U.S. Executive Office of the President, Washington, DC.

Paté-Cornell, M.E. and Guikema, S., 2002. "Probabilistic Modeling of Terrorist Threats: A Systems Analysis Approach to Setting Priorities among Countermeasures.” Military Operations Research, 7:5-20.

Weil, R. and Apostolakis, G.E., 2001. "A methodology for the prioritization of operating experience in nuclear power plants." Reliability Engineering and System Safety, 74:2342.

Zio, E., Podofillini, L., and Zille, V., 2006. "A Combination of Monte Carlo Simulation and Cellular Automata for Computing the Availability of Complex Network Systems," to appear in Reliability Engineering and System Safety. 
(This page intentionally left blank) 


\section{Appendices}




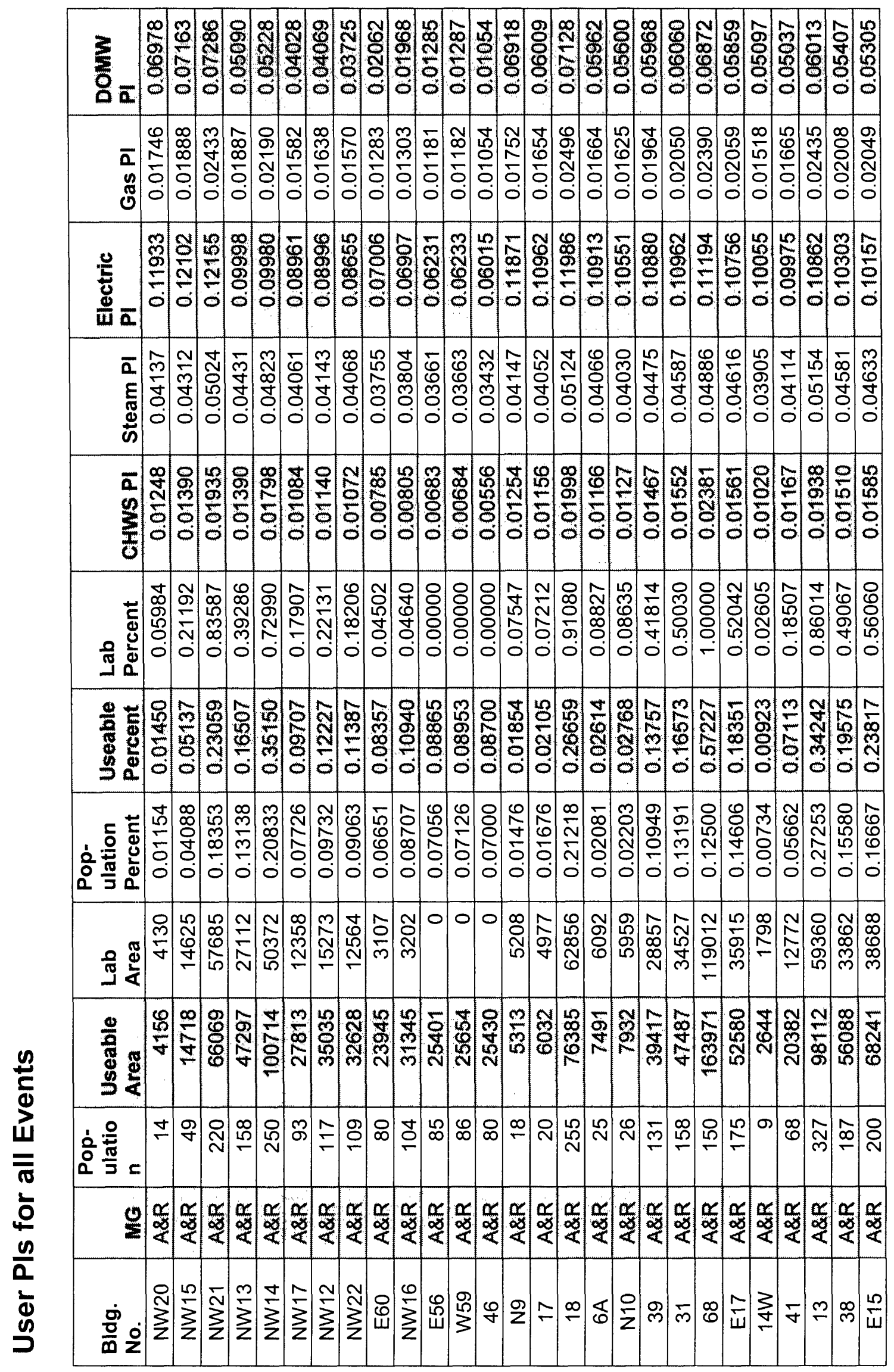




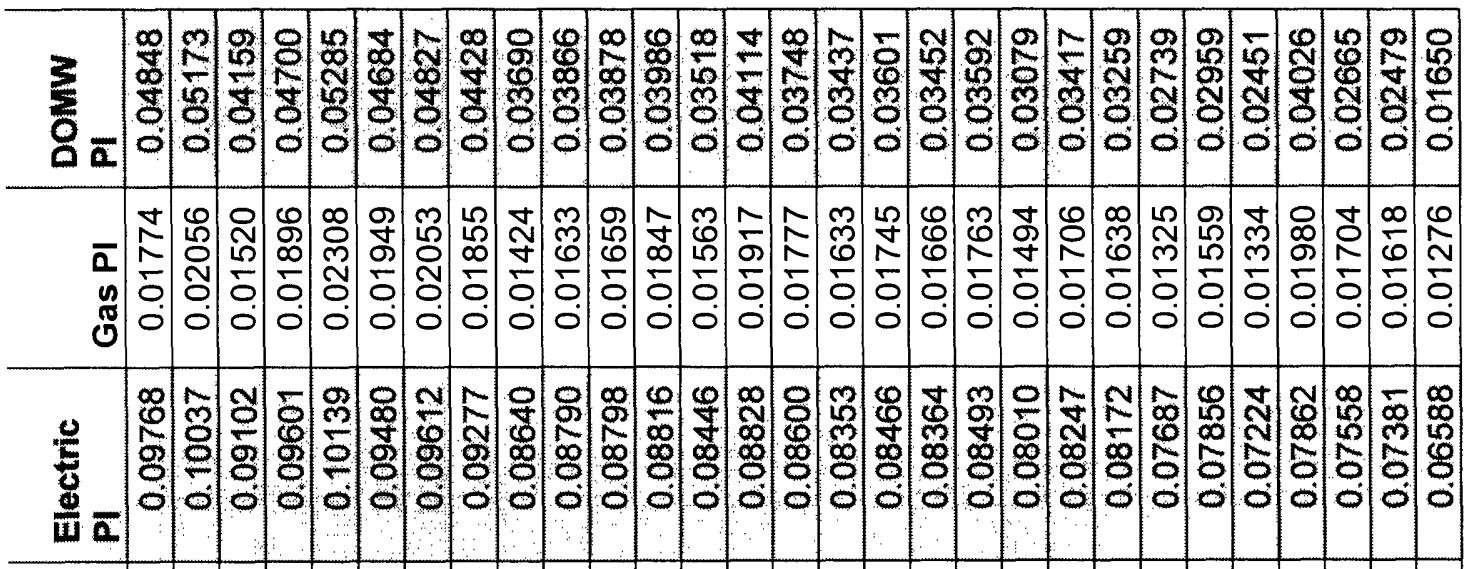

ฉ

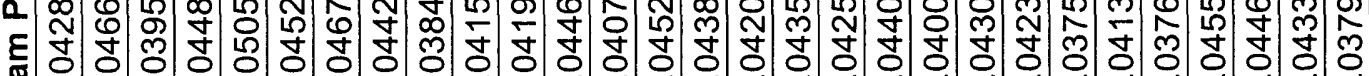

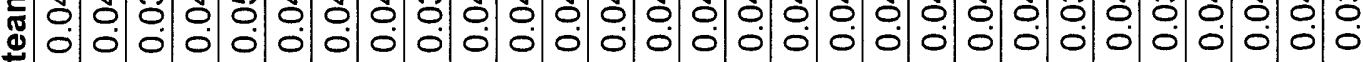
$\dot{\boldsymbol{D}}$

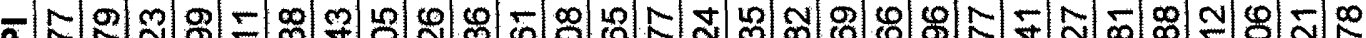

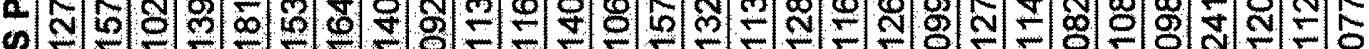

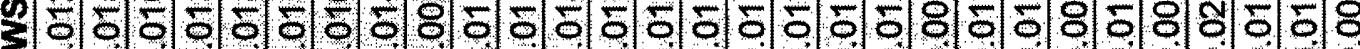

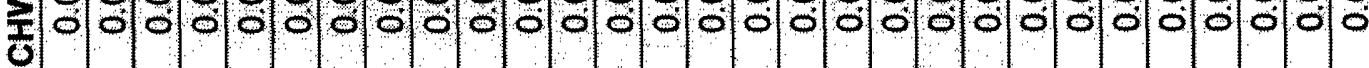

ப స్ల ఏ̊m 号

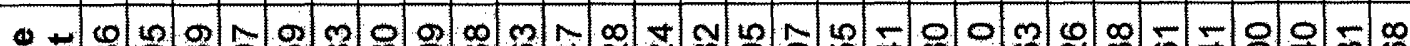

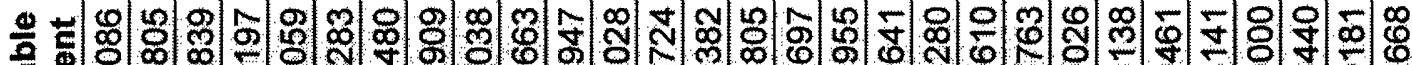

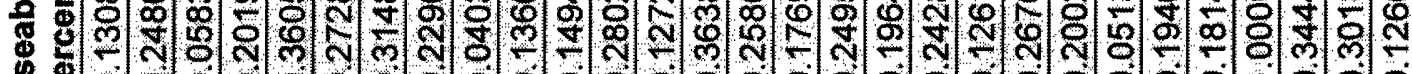
$\checkmark$ :

ம 。

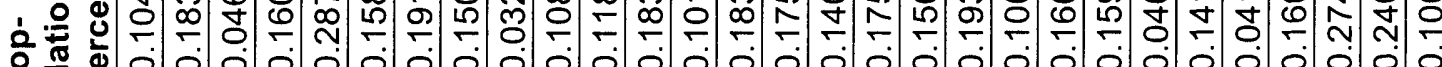

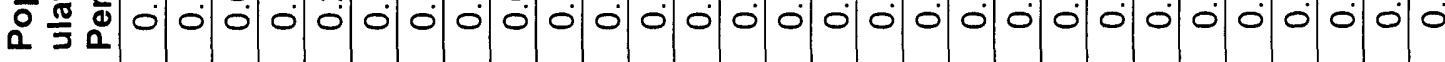

m

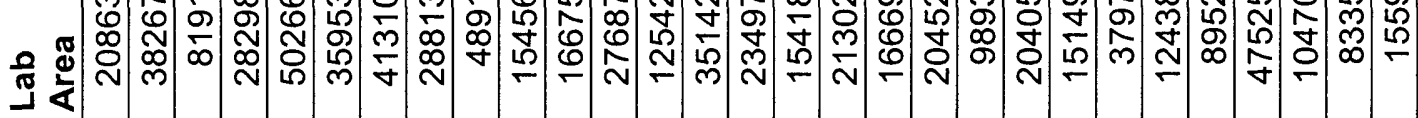

(2)

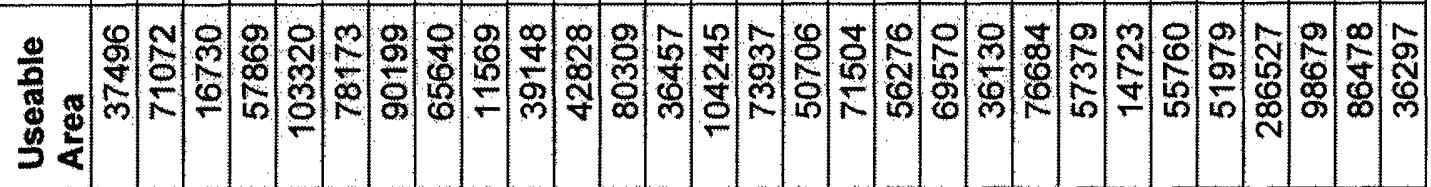

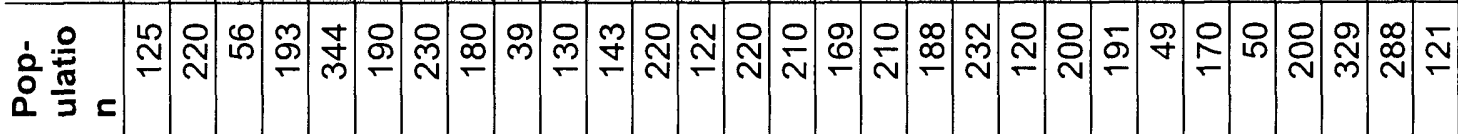

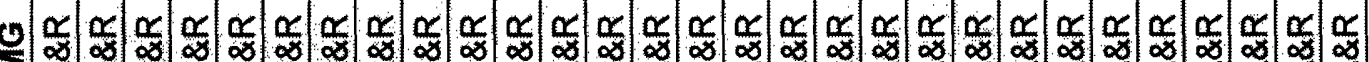
닌

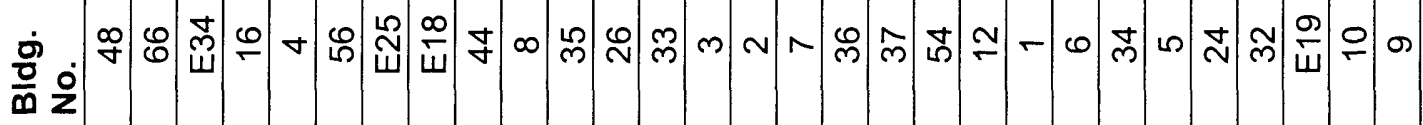


言

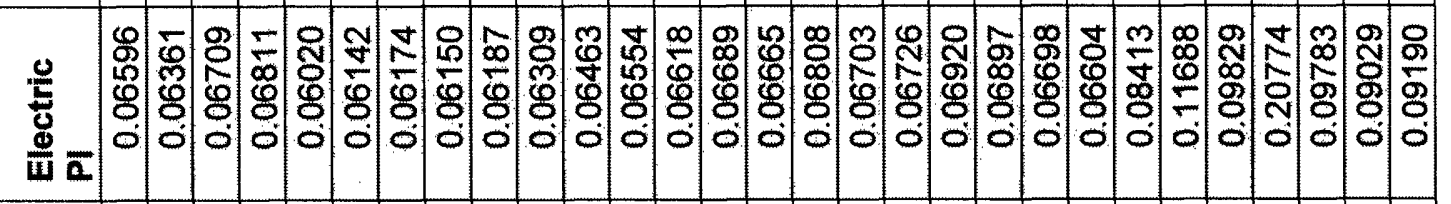

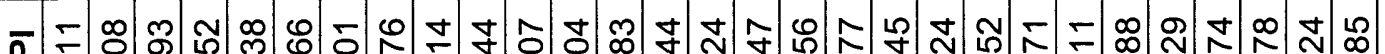

ร દ్లి

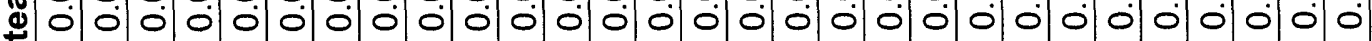
ஸे

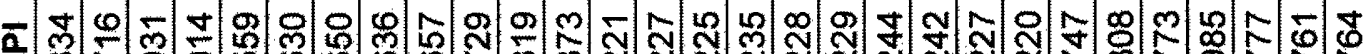
3ิ II

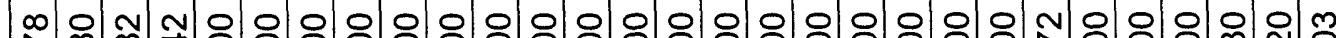
ت

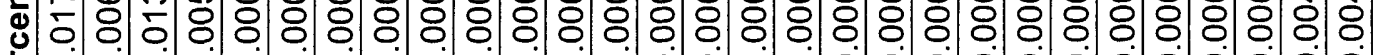
重 \lrcorner 0

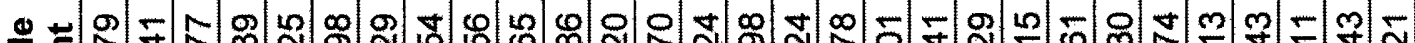

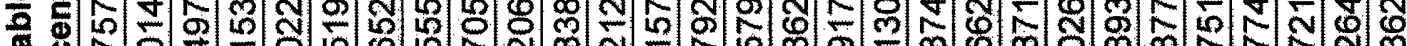
원원

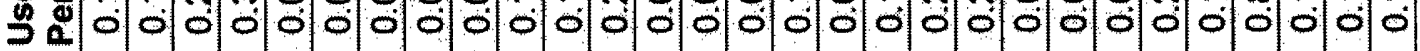

ᄃ

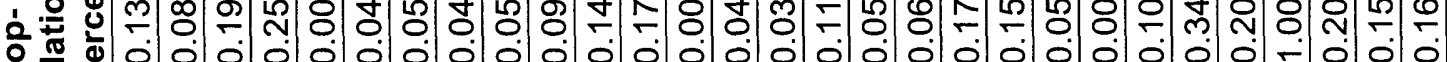

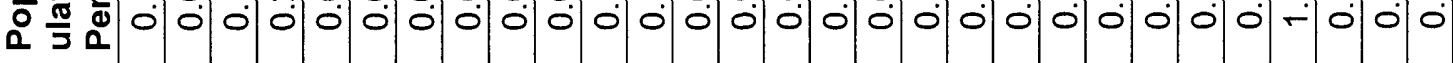
。ำ ฐ

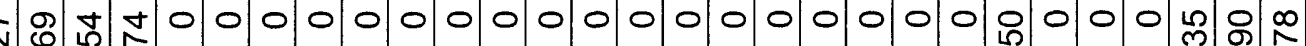
画

1 00 잉

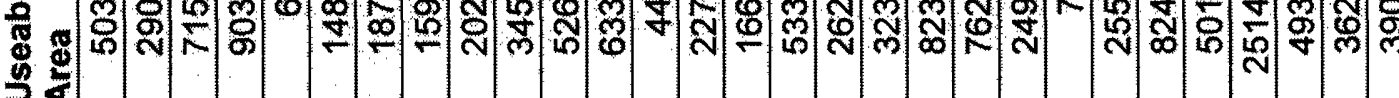

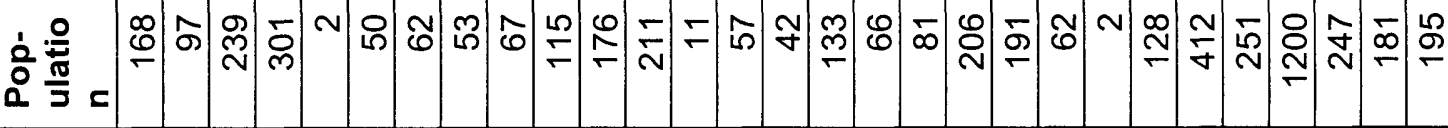

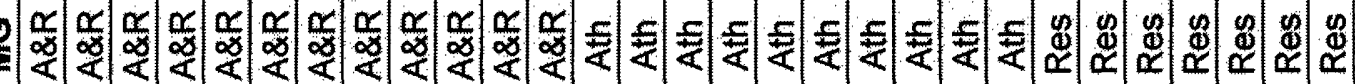

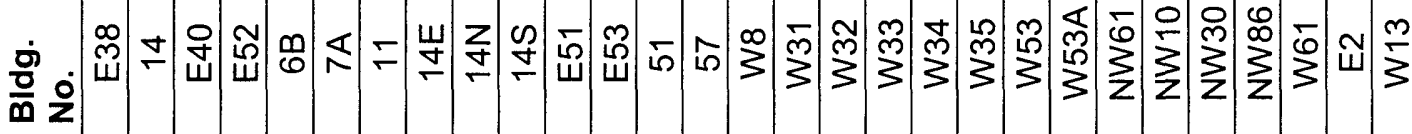




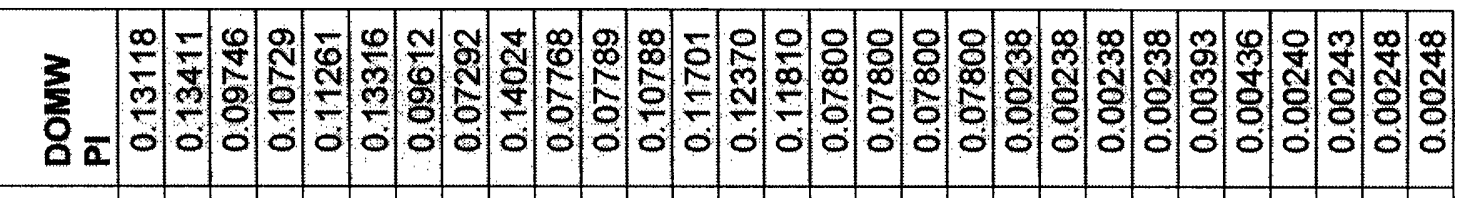

த N

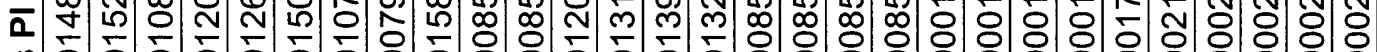
心్

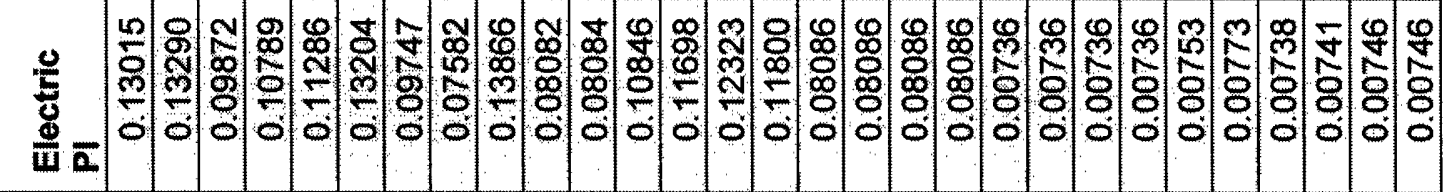

a F

ع

든

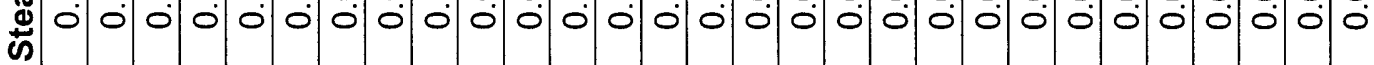

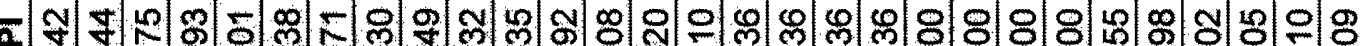

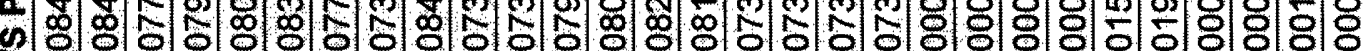
3.

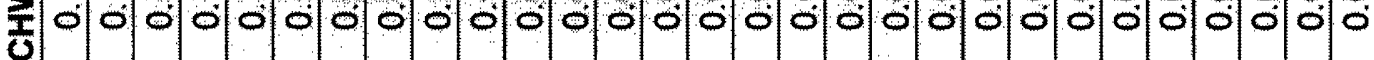

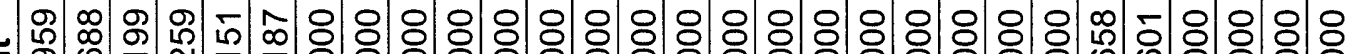

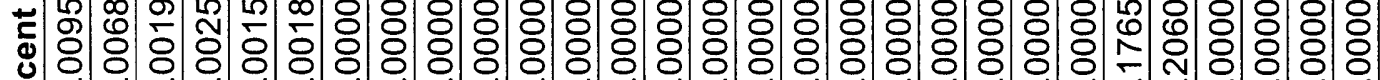
先

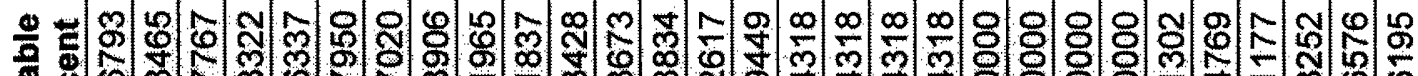

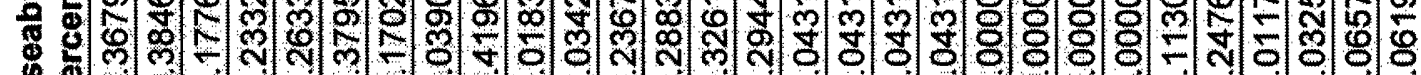

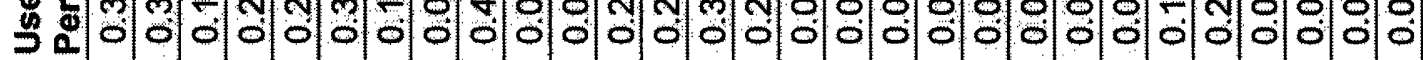

- 워 눙

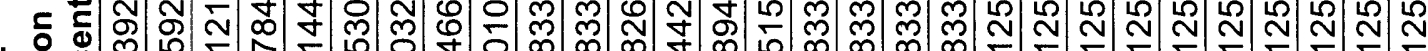
之. Q

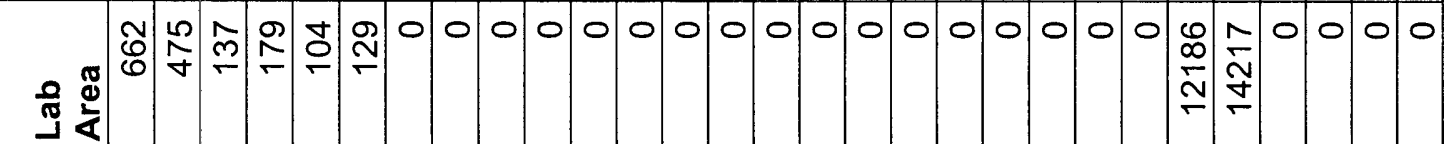

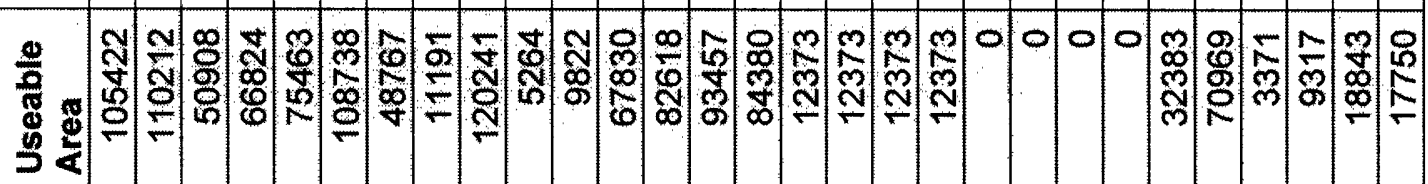

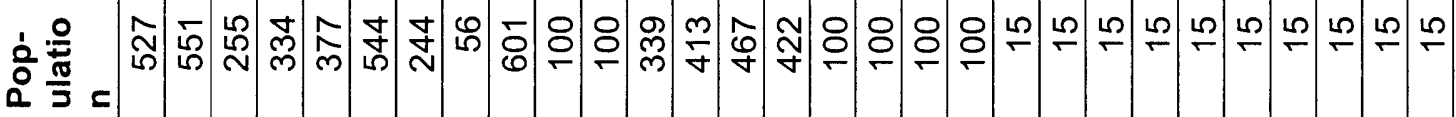

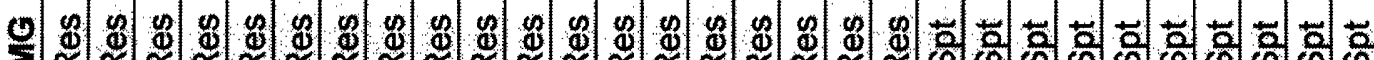

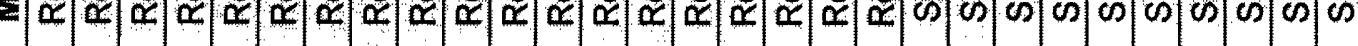

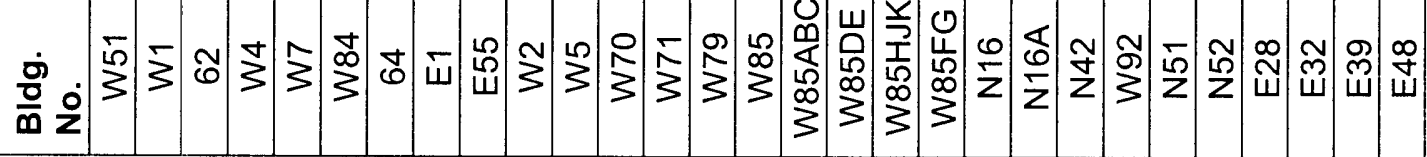




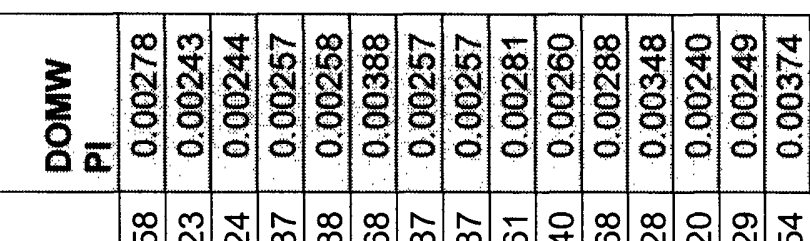

-

п

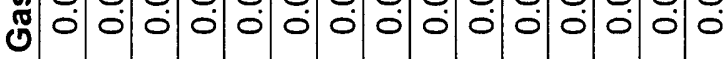

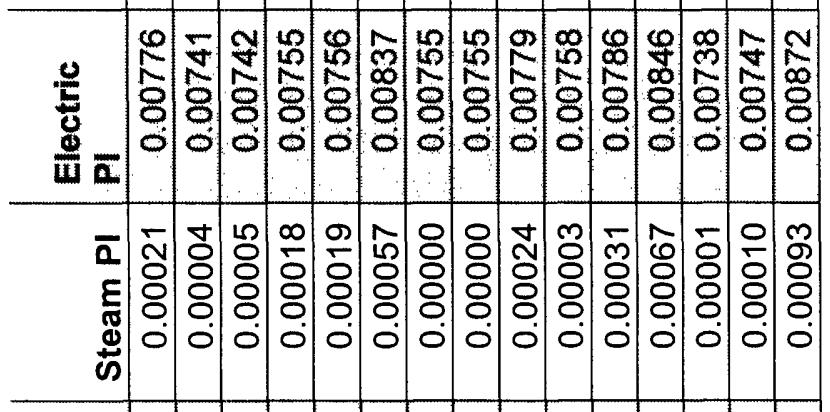

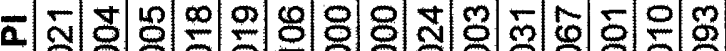

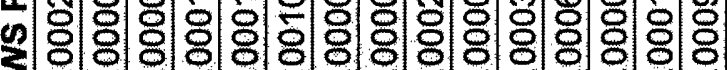
두이일

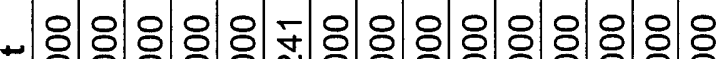

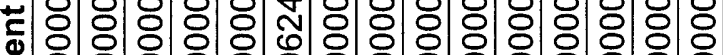

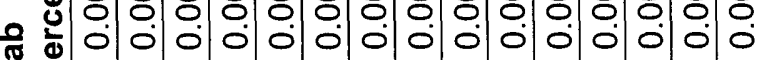
苟文

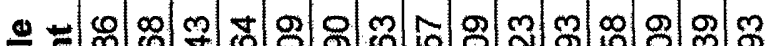
능 웡 今

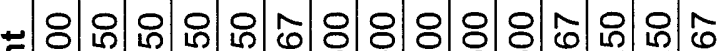
ᄃ

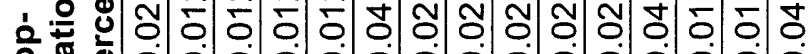
:

\begin{tabular}{|c|c|c|c|c|c|c|c|c|c|c|c|c|c|c|}
\hline 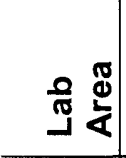 & 0 & 0 & 0 & 0 & 0 & స్. & 0 & 0 & 0.0 & 0 & 00 & 10 & $c$ & 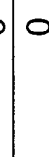 \\
\hline $\begin{array}{l}\frac{0}{5} \\
\stackrel{5}{8} \\
5 \\
5\end{array}$ & $\frac{8}{2}$ & 요 & $\frac{5}{6}$ & 8 & 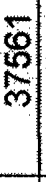 & $\frac{\varphi}{5}$ & 感 & 5 & $\frac{5}{6}$ & 8 & $\frac{5}{5}$ & & & \\
\hline$\frac{2}{\frac{2}{0}} \frac{0}{\frac{\pi}{5}}$ & ஜ) & 2 & 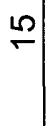 & $\stackrel{0}{2}$ & $\stackrel{2}{2}$ & 오 & థి & ஓి & 이 & ৪্ল & D) & $\underline{\sigma}$ & s. & 2 \\
\hline$\frac{0}{\Sigma}$ & के & के & के & के & क् & के & के & क् & के & के & 苟 & & 5 & |े \\
\hline$\frac{\bar{\sigma}}{0} \frac{0}{2}$ & $\frac{1}{2}$ & $\sum$ & $\begin{array}{l}\infty \\
\infty \\
3\end{array}$ & $\sum_{\substack{0 \\
0}}^{1}$ & $\sum_{5}^{\infty}$ & $\stackrel{\text { D }}{3}$ & $\varangle$ & $\underset{\mathbb{N}}{\longleftarrow}$ & 유 & & $\begin{array}{r}\mathscr{y} \\
\mathrm{w}\end{array}$ & 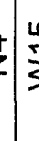 & $\frac{1}{3}$ & $=\frac{10}{8}$ \\
\hline
\end{tabular}




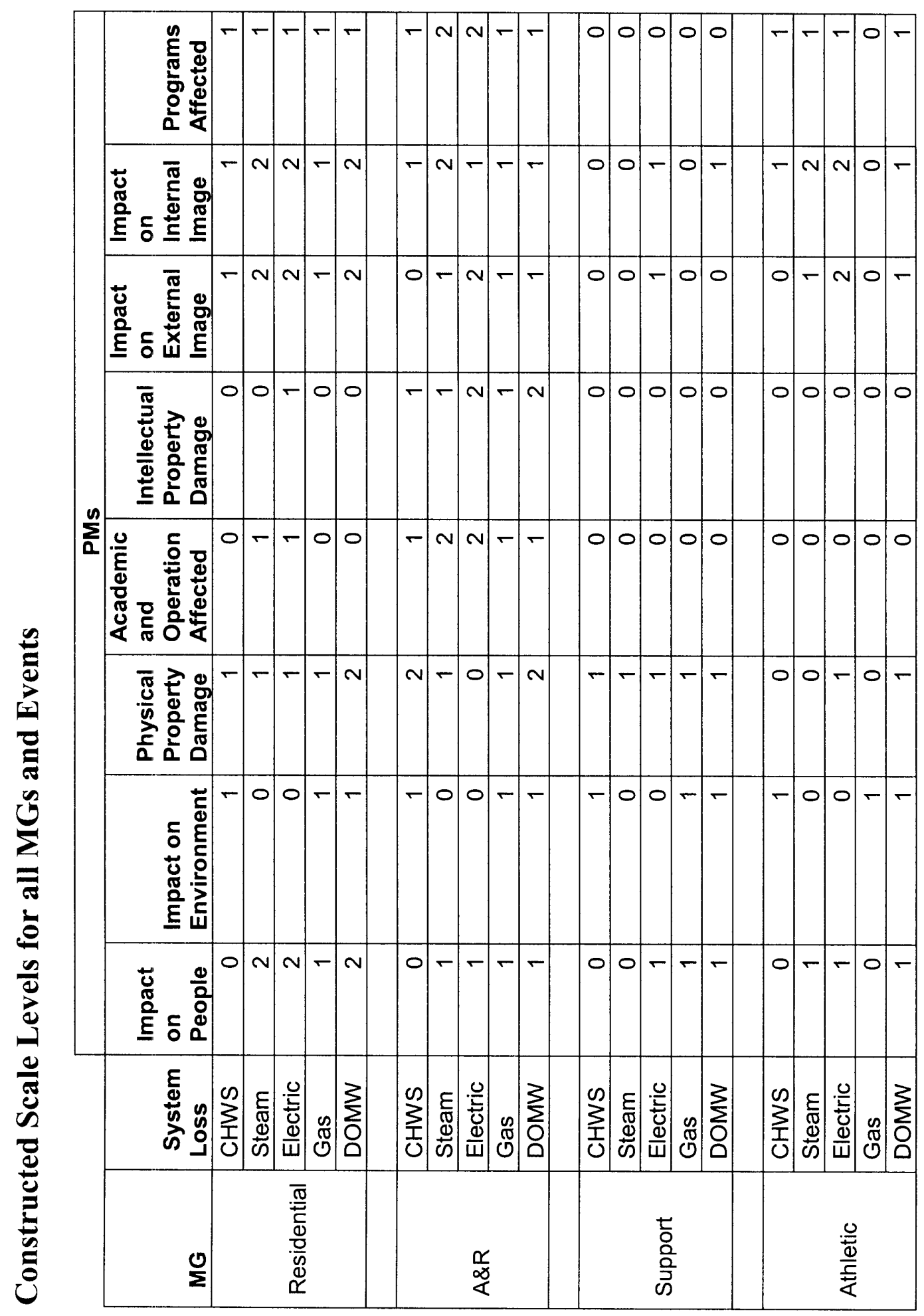

